\title{
Arm Movements Induced by Electrical Microstimulation in the Superior Colliculus of the Macaque Monkey
}

\author{
Roland Philipp ${ }^{1,3}$ and Klaus-Peter Hoffmann ${ }^{1,2}$ \\ ${ }^{1}$ Faculty of Biology and Biotechnology and ${ }^{2}$ Department of Neuroscience, Ruhr University, 44780 Bochum, Germany, and ${ }^{3}$ Sobell Department of Motor \\ Neuroscience and Movement Disorders, University College London Institute of Neurology, London, United Kingdom WC1N 3BG
}

\begin{abstract}
Neuronal activity in the deep layers of the macaque (Macaca mulatta) superior colliculus (SC) and the underlying reticular formation is correlated with the initiation and execution of arm movements (Werner, 1993). Although the correlation of this activity with EMGs of proximal arm muscles is as strong as in motor cortex (Werner et al., 1997a; Stuphorn et al., 1999), little is known about the influence of electrical microstimulation in the SC on the initiation and trajectories of arm movements. Our experiments on three macaque monkeys clearly show that arm movements can be elicited by electrical microstimulation in the deep layers of the lateral SC and underlying reticular formation. The most extensively trained monkey, M1, extended his arm toward the screen in front of him more or less stereotypically upon electrical SC stimulation. In two other monkeys, M2 and M3, a larger repertoire of arm movements were elicited, categorized into three movement types, and compared before (M3) and after (M2 and M3) training: twitch (56\% vs 62\%), lift (6\% vs 5\%), and extend (37\% vs 32\%), respectively. Therefore, arm movements induced by electrical stimulation in the monkey SC represent a further component of the functional repertoire of the SC using its impact on motoneurons in the spinal cord, probably via premotor neurons in the brainstem, as well as on structures involved in executing more complex movements such as target-directed reaching. Therefore, the macaque SC could be involved directly in the initiation, execution, and amendment of arm and hand movements.
\end{abstract}

Key words: electrical microstimulation; forelimb movement; midbrain; nonhuman primate; reticular formation; superior colliculus

\section{Introduction}

Elaboration of sensory input for orienting is complex because the information is usually provided by different channels. Therefore, sensory information from different reference systems (e.g., retinocentric or head or body centered) has to be integrated and transformed into a new dynamic reference system for arm movement (Snyder, 2000). Due to the ability of the superior colliculus (SC) for multisensory integration (Meredith and Stein, 1983, 1986a, 1986b) and translation of signals into motor commands controlling saccadic eye and head movements (Wurtz and Goldberg, 1971; Walton et al., 2007), as well as the existence of reach related neurons in the monkey's SC (Werner, 1993; Werner et al., 1997a, 1997b), this structure is exquisitely suited to study its contributions to orienting behavior including goal-directed arm movements. Recently, arm-movement-related activation has been identified also in the human SC (Linzenbold and Himmelbach, 2012).

\footnotetext{
Received Jan. 30, 2013; revised Jan. 17, 2014; accepted Jan. 26, 2014

Author contributions: R.P. and K.-P.H. designed research; R.P. and K.-P.H. performed research; R.P. analyzed data; R.P. and K.-P.H. wrote the paper.

This work was supported by the German Science Foundation (SFB-509 "Neurovision") and the Hertie Foundation (ZEN). We thank Claudia Distler for surgical procedures, Dieter F. Kutz for the design of the setup, Hermann Korbmacher for providing the glass-insulated tungsten electrodes, Stefan Dobers and Abdulhakim Al-Hakim for technical support, Margit Bronzel for animal care, the Grönemeyer Institute for MRI scans, Werner Lindner for assisting with recordings, and Jacqueline S. How for reviewing the manuscript.

Correspondence should be addressed to Prof. Dr. Klaus-Peter Hoffmann, Faculty of Biology and Biotechnology ND 5/26, Ruhr University Bochum, D-44780 Bochum, Germany. E-mail: kph@neurobiologie.rub.de.

DOI:10.1523/JNEUROSCI.0443-13.2014

Copyright $\odot 2014$ the authors $\quad 0270-6474 / 14 / 343350-14 \$ 15.00 / 0$
}

Microstimulation has implicated the SC or its homologue in lower vertebrates, the optic tectum, in controlling skeletomotor functions such as whole-body turning in freely moving cats (Hess et al., 1946), whole-body orienting or avoidance in rodents (Sahibzada et al., 1986), prey catching in toads (Ewert, 1984), or turning movements in goldfish (Akert, 1949). Striking evidence for the contribution of collicular neurons to forelimb and hindlimb movements in the cat were provided by Anderson et al. (1972), who demonstrated that electrical microstimulation in the deep SC evokes EPSPs in flexor and extensor limb motoneurons. First hints for a possible participation of the monkey SC in visually guided skeletomotor behavior came from anatomical studies (Kuypers and Lawrence, 1967; Goldman and Nauta, 1976; Catman-Berrevoets et al., 1979) identifying projections from cortical areas involved in skeletomotor behavior to terminate in the intermediate and deep layers of the SC (Fries, 1984, 1985; Borra et al., 2010, 2012). Furthermore, targets of descending projections from the deep layers of the lateral SC in rat, cat, and monkey indicate that skeletomotor functions other than head movements could also be mediated by the SC (Castiglioni et al., 1978; Grantyn and Grantyn, 1982; Olivier et al., 1991; Nudo et al., 1993; Rubelowski et al., 2013). Finally, applying electrical microstimulation within the deep layers of the macaque, Cowie and Robinson (1994) could not only evoke head movements, but in some penetrations, also movements of the proximal limbs. Effective stimulation sites were usually found below those from which head movements could be elicited. 
A first series of experiments conducted in our laboratory on a monkey (M1) highly trained to perform goal-directed arm movements (Lindner, 2004) showed that microstimulation in the SC could cause similar reaches. Therefore, a second series of experiments was performed in a naive monkey (M3) before any arm movement training to confirm that SC stimulation can indeed elicit arm movements in a monkey independently of learned behavioral content. These results were complemented and confirmed by a third, moderately trained monkey (M2), in which the arm ipsilateral to the stimulated SC was also probed. These results have been published in part in abstract form (Philipp et al., 2006).

\section{Materials and Methods}

Animals. Three male rhesus monkeys (Macaca mulatta), M1, M2, and M3, weighing $11,8.5$, and $10.5 \mathrm{~kg}$, respectively, took part in these experiments. Two monkeys (M1 and M2) were trained to perform saccades coupled with reaches toward visual stimuli. In the late phase of these experiments, electrical stimulation was applied to the SC. The naive monkey, M3, was only familiarized with the experimental setup and trained in a standard fixation paradigm, which was necessary to determine the visual receptive field locations in the superficial layers of the SC before electrical stimulation was applied. After the completion of the initial stimulation experiments in monkey M3, training for the execution of arm movements to visual targets on the screen was initiated (blue LED). During the experiments, the body was restrained in a primate chair. The head was free to move for monkeys M1 and M3, whereas monkey M2's head was restrained. Visual targets (red and blue LEDs; 1 $\mathrm{cm}$ diameter, $1.5 \mathrm{~cd} / \mathrm{m}^{2}$ ) were rear projected on a $60-\mathrm{cm}$-wide, circular, translucent tangential screen $27.5 \mathrm{~cm}$ in front of the animal in complete darkness via galvanometer-driven mirrors under homemade software control. The monkeys' gaze and hand position were monitored with the same software that recorded the spike events. For details of the paradigms, see section "Experimental procedures."

Procedures. All procedures were designed to minimize the discomfort and pain of the animals. All experiments were approved by the local ethics committee and performed in accordance with the Deutsche Tierschutzgesetz of 7-26-2002, the European Communities Council Directive of 86609 EEC, and the NIH Guide for the Care and Use of Laboratory Animals. Subjects M1 and M3 also participated in related experiments (Reyes-Puerta et al., 2009, 2010, 2011).

Surgery. After an initial training period, the monkeys were prepared for eye movement and extracellular single-cell recording. The monkeys were treated preoperatively with atropine sulfate $(0.04 \mathrm{mg} / \mathrm{kg})$ and initially anesthetized with ketamine hydrochloride $(10 \mathrm{mg} / \mathrm{kg}, \mathrm{i} . \mathrm{m}$. $)$ followed by supplementary doses of pentobarbital sodium as needed ( 25 $\mathrm{mg} / \mathrm{kg}$, i.v.). Deep analgesia was maintained by intravenous bolus applications of fentanyl $(3 \mu \mathrm{g} / \mathrm{kg} / \mathrm{h})$.

A custom-made head holder (stainless steel or titanium) was fixed to the skull with surgical screws and was additionally embedded in dental acrylic together with the SC recording chamber. The center of the chamber (inner diameter: $19 \mathrm{~mm}$ ) was stereotaxically placed at Horsley-Clarke coordinates on the midline over the occipital pole and tilted backwards $45^{\circ}$ from the vertical to ensure an approximately perpendicular approach through the SC layers. Stereotaxic coordinates were adjusted according to a prior anatomical magnetic resonance scan with a Siemens Magnetom (1.5 tesla). A subconjunctival search coil (Bioflex wire) was implanted in one eye as described by Fuchs and Robinson (1966) and modified by Judge et al. (1980). Heart rate, blood pressure, body temperature, and the oxygen saturation of the blood were monitored for the duration of the surgery. Analgesics and antibiotics were administered intramuscularly for 1 week postoperatively. Wound treatment was performed in a daily procedure in which the recording chamber was additionally supplied with antibiotic eye drops.

Recording. For extracellular recordings and electrical microstimulation, a guide tube penetrated the dura mater, and home-made glassinsulated tungsten microelectrodes (tip diameter $2 \mu \mathrm{m}, 0.5-1.5 \mathrm{M} \Omega$ or tip diameter $1 \mu \mathrm{m}, 2-3 \mathrm{M} \Omega$ measured at $100 \mathrm{~Hz}$ for stimulation and recording experiments, respectively) were lowered into the brain by a microdrive (MO-95, meter reading accuracy: $10 \mu \mathrm{m}$; Narishige International) attached to the recording chamber. Recorded signals were preamplified, digitized, and transmitted via interference-free fiber optics to the main amplifier. The signal was fed through a computer-controlled realtime spike-sorting system using an online time-amplitude window discriminator (Plexon) and stored as spike times with $1 \mathrm{~ms}$ resolution.

Horizontal and vertical gaze-position signals were measured via a magnetic search-coil system (EM3 eye movement monitor; Remmel Labs) at $500 \mathrm{~Hz}$. With the head unrestrained, an additional search coil was attached to the head. The gaze-position signal was used to monitor stable fixation in a window of $2.5^{\circ}$ radius around the fixation point during the tasks.

One arm was restrained and the other either contralateral or ipsilateral to the electrically stimulated SC was kept unrestrained during the experiments. Arm position was recorded at $91 \mathrm{~Hz}$ by means of a magnetic sensor attached to the monkey's active wrist (miniBird system, $0.5 \mathrm{~mm}$ resolution; Ascension Technology).

All data were fed into a PC-ISA multifunction board (PCI-20098C; Intelligent Instrumentation) and stored on the hard disk of the same computer that controlled the animal's behavior for offline analysis. In addition, behavior was monitored via an infrared camera system (SSCM370CE; Sony) and stored on a DVD hard disc recorder (DMREH56; Panasonic). One audio channel of the recorder was used to store the timing of each new behavioral event; the second channel recorded the onset and duration of the electrical microstimulation This served to correlate the monkey's behavior with the microstimulation during the analysis of the DVD recordings.

Experimental procedure. Before electrical stimulation, the depth of the collicular surface was determined by multiunit recording, and visual receptive fields were plotted in a standard fixation task. This was necessary to determine the stimulation site within the collicular visuomotor map. The microstimulation protocol started always in depths between 500 and $1000 \mu \mathrm{m}$ below the SC surface and ended at $\sim 5700 \mu \mathrm{m}$ (after continuous probing every $100 \mu \mathrm{m}$ ).

A stimulation site was considered effective if one of the arm movement types or a combination of them (as described in Data analysis, below) was elicited successfully; that is, it was clearly visible on the TV monitor or discernible in the arm position traces at least three times within 10 trials. Ineffective sites were left after maximal 10 repetitions with maximal 50 $\mu \mathrm{A}$ stimulus current.

Cathodal pulse trains of $400 \mu$ s pulse width, $200-500 \mathrm{~ms}$ duration, and frequencies of $200-300 \mathrm{~Hz}$ at stimulus strengths slightly higher than those eliciting saccades $(5-10 \mu \mathrm{A})$ were applied to test whether movements of the unrestrained arm could be elicited. From time to time, polarity was changed briefly to avoid polarization of the electrode. The parameters used in this experiment, electrical stimulation on $\sim 0.2$ to half-second time scale with currents $<50 \mu \mathrm{A}$, follow the commonly and successfully used parameters to study eye-and-head shifts in the superior colliculus (Cowie and Robinson, 1994; Freedman et al., 1996; Corneil et al., 2002; Klier et al., 2003) and to study complex movements of the arm evoked from the motor cortex (Graziano et al., 2002, 2005). It is important to monitor the current flowing across the microelectrode into the tissue. We therefore used a constant current isolation unit and displayed form and amplitude of the pulses on an oscilloscope. Rise time of the isolation unit to the desired amplitude was about $100 \mu$ s across $1 \mathrm{M} \Omega$.

At effective stimulation sites, the experimental procedure was started using currents that elicited at least twitches of the wrist (current range: $10-50 \mu \mathrm{A}$, median currents: $30 \mu \mathrm{A}, 25$ th: $21 \mu \mathrm{A}, 75$ th: $35 \mu \mathrm{A}$ ). Twenty consecutive trials of electrical microstimulation were sampled at each stimulation site. All experiments were conducted in total darkness. The monkeys were not engaged in a particular behavioral task during stimulation. Microstimulation was delivered manually and at random times (with a minimum delay of $10 \mathrm{~s}$ between repetitions) when the hand was at rest mostly in front of the trunk or at the start bar or at some other target on the primate chair (water tube). We did not notice an effect of initial hand position except that the monkeys could suppress extend movements by holding tightly to the chair. These tests were discarded from analysis. During the microstimulation experiments, the highly trained 


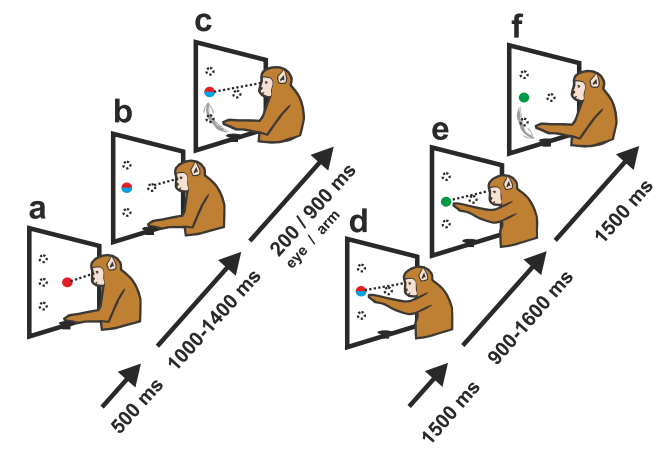

Figure 1. SR paradigm: Sketches $(a-f)$ describe the behavioral sequence of the SR paradigm. Arrows and accompanying times (ms) describe the temporal sequence in completed trials. Temporal sequence is the same for all three targets. The monkey needs to perform a saccade (red target) and arm movement (blue target) as soon as the central fixation target disappears (go signal). For a detailed description, see Materials and Methods.

monkey M1 was rewarded after each stimulation trial whether an arm movement could be elicited or not. In contrast, the naive monkey M3 and the moderately trained monkey M2 were never rewarded after electrical stimulation to avoid any causal relationship between electrical microstimulation and reward. After 11 experimental days, the naive monkey M3 was trained to perform different tasks regarding eye-hand coordination including fixation-reach and saccade-reach tasks. After 5 months of this training, electrical microstimulation experiments were repeated to investigate whether arm movement training affected the monkey's reach behavior or not.

In the saccade-reach (SR) task, the monkey was instructed to carry out combined eye and arm movements to one of three possible peripheral targets. One target appeared $24^{\circ}$ eccentric in the visual hemifield contralateral to the stimulated SC; the other two targets were presented $10^{\circ}$ below and above the middle target (Fig. 1). At the beginning, the monkey had to fixate the central red target $\left(2.5^{\circ}\right.$ radius $)$ for $1000-1400 \mathrm{~ms}$. After this fixation period, the fixation target disappeared and reappeared together with the blue reach target in the visual periphery. The subject had to look at and touch the new targets within $1500 \mathrm{~ms}$ after button release or the trial was aborted. After a hold time of $900-1600 \mathrm{~ms}$, the blue reach target turned off and the red fixation target changed its color to green, which signaled the successful execution of the trial.

Data analysis. All data were analyzed offline by home-made software using MATLAB (MathWorks). Gaze position signals were filtered using a second-order low-pass butterworth filter with a $28 \mathrm{~Hz}$ cutoff frequency. For recording arm movement trajectories, a second-order low-pass butterworth filter with a $7 \mathrm{~Hz}$ cutoff frequency was used. The median onset latencies of the arm movements were detected by a speed threshold criterion ( $10 \%$ of maximum speed; Sailer et al., 2003) within a time window starting at microstimulation onset and lasting for $1000 \mathrm{~ms}$. Instantaneous arm movement speed was calculated from the three-dimensional position data provided by the miniBird sensor. Video recordings were further used to characterize the arm movements offline. Three arm movement types were defined by visual inspection and quantitative amplitude criteria: (1) twitch movements of the thumb, hand, or wrist (amplitude: $\leq 10 \mathrm{~mm}$ ); (2) lift movements of the forearm (>10 mm mainly in the Y direction); and (3) extend movements of the arm with a clear transport component of the hand away from the hand rest and amplitudes $\geq 100 \mathrm{~mm}$ (Fig. 2).

To compare the probabilities $(P)$ that different movement types can be elicited from the same stimulation site within the SC an index was calculated as follows: index $=\left(P_{\text {twitch\&lift }}-P_{\text {extend }}\right):\left(P_{\text {twitch\&lift }}+P_{\text {extend }}\right)$. Statistical tests were used to test the hypothesis that two independent samples containing arm movement latencies represent similar distributions. First, each distribution of data was tested for normality (Kolmogorov-Smirnov) within each group. For a non-normal distribution, the nonparametric Mann-Whitney $U$ test was used. In all other cases, the parametric Student's $t$ test for independent samples was performed. A Kruskal-Wallis one-way ANOVA on ranks and the pairwise multiple- comparison procedure after Dunn's method were used to compare many groups with each other. For the comparison of calculated or counted quantities, a $\chi^{2}$ test was used to test for significantly varying distributions. To compare the proportions from two independent groups, a onetailed $Z$ test was used. All tests were applied at the $5 \%$ significance level for between-group comparisons. Tests were conducted in MATLAB or SigmaStat (Systat Software).

\section{Results}

The experiments on three macaque monkeys show that arm movements can be elicited by electrical microstimulation in the deep layers of the SC and the underlying reticular formation. The direction and amplitude of the evoked arm movements could not be related to the concomitantly occurring gaze shifts, confirming our published electrophysiological results that there is no visuomotor map for arm movements in the SC (Werner et al., 1997b). This conclusion is similar to that reached for head movement control: the lack of a topographical organization of headmovement-related neurons in the SC based on their head movement field properties (for review, see Gandhi and Katnami, 2011). The most extensively trained monkey, M1, extended his contralateral arm toward the screen in front of him more or less stereotypically upon electrical stimulation in the SC (Fig. 2A,B). Microstimulation in the SC of M1 was effective to elicit arm movements in 16 of 17 experimental sessions. The actions elicited in the lesser trained monkeys, M2 and M3, were less stereotypical than those of monkey M1 and disclosed a large repertoire of arm movements, which were classified into one of three movement types by visual inspection and quantitative amplitude criteria: (1) twitch: minor movements of thumb, hand, or shoulder with amplitudes $\leq 10 \mathrm{~mm}$; (2) lift: moderate movements of the hand or shoulder with amplitudes $>10 \mathrm{~mm}$; and (3) extend: large movements of the arm with amplitudes $\geq 100 \mathrm{~mm}$ (Fig. 3). In monkey $\mathrm{M} 2$, the effect of microstimulation on both the ipsilateral and the contralateral arm was tested. During 10 experimental sessions, 10 penetrations were performed in M2, six of which were effective in eliciting arm movements. A total of 650 microstimulations were applied while probing the contralateral arm and 260 while probing the ipsilateral arm, 357 and 177 of which successfully elicited arm movements, respectively. Importantly, in monkey M3, electrical microstimulation before any arm movement trainingthat is, without any experience in performing arm movements to visual targets within the experimental setup — resulted in similar movement types as in M2. Overall, microstimulation was conducted along 68 penetrations covering the entire rostrocaudal and mediolateral extend of the SC in monkey M3. The 18 penetrations in which arm movements could be elicited were restricted to the lateral SC (see Figs. 9, 11). Of 1579 microstimulations applied during these 18 penetrations, 238 of 500 were effective before (five penetrations) and 661 of 1079 after the arm movement training (13 penetrations).

\section{Movement characteristics}

Arm position in $X$-coordinates (horizontal), $Y$-coordinates (vertical), and $Z$-coordinates (toward screen) versus time of the most conspicuous arm movements ("extend") electrically elicited from a given SC stimulation site are shown for monkey M1 in Figure $2 A$ and for M3 before the training in Figure $2 C$. The microstimulation period is represented by the black bar starting at time point zero (200 impulses per second for $200 \mathrm{~ms}$ ). All arm movements start within a $500 \mathrm{~ms}$ time window after microstimulation onset. The initial movement onset is occasionally followed by submovements of different direction and amplitude. The arm trajectories are additionally shown in three dimensions in Figure 
A
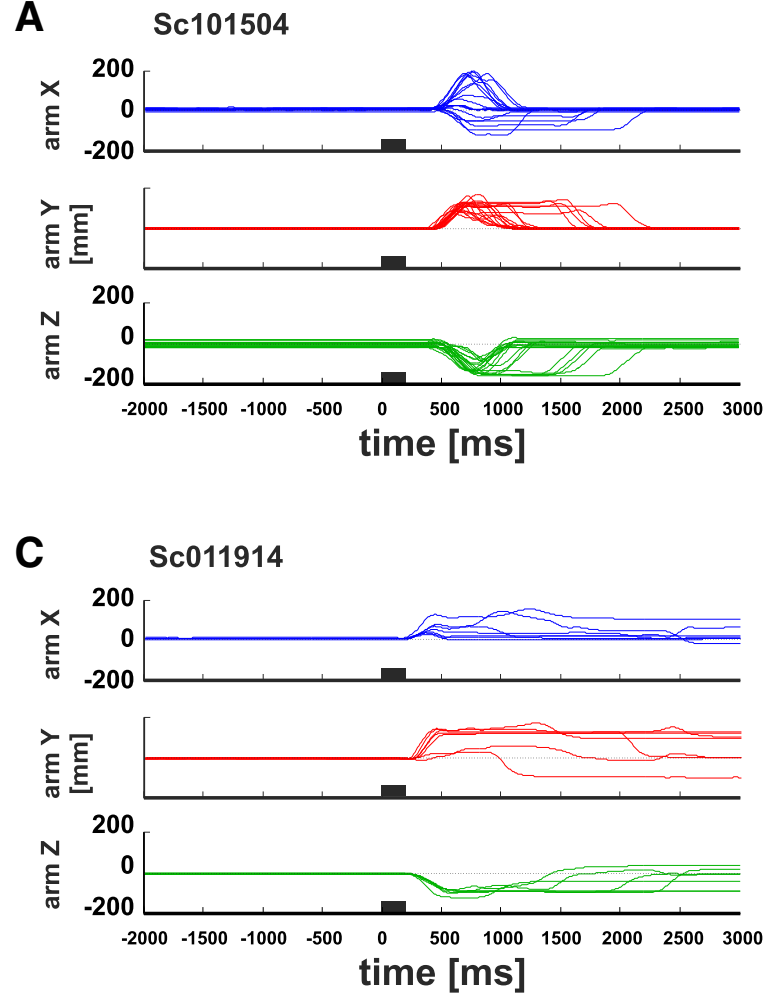

B
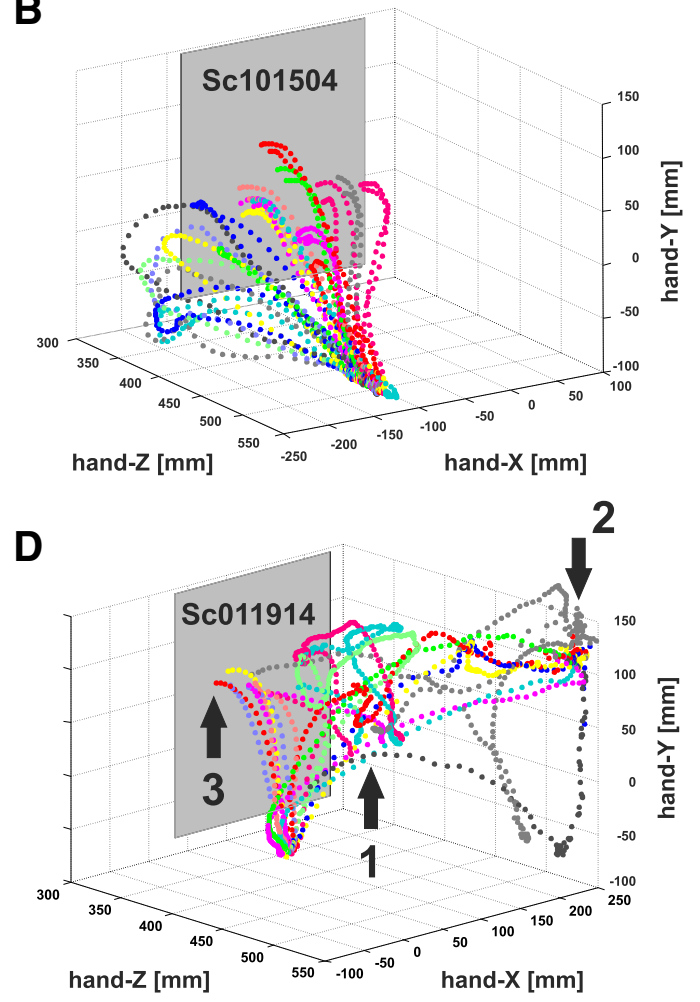

Figure 2. Example trajectories for monkey M1 and M3. A, Typical arm positions for monkey M1. $X, Y$, and Z coordinates of the arm position ( $\mathrm{mm}$ ] are plotted on the $y$-axes over time (ms) on the $x$-axis. All traces are aligned to microstimulation onset (time $=0$ ). Black bars on the $x$-axis represent the start and end of the applied microstimulation. Plotted is the change in position with respect to the pre-stimulation period $(\mathrm{mm}=0) . \boldsymbol{B}$, Illustration of the same trajectories in three dimensions during the first $2000 \mathrm{~ms}$ after stimulation onset. The workspace is defined as follows: $x$-axis runs horizontally, $y$-axis vertically parallel to the screen, and the $z$-axis describes the depth (i.e., the distance between the monkey and the screen). The origin of the coordinate system is represented by the magnetic field source behind the screen. $C$, shows the $X, Y$, and $Z$ positions for typical arm movements of monkey M3. D, Corresponding three-dimensional illustrations for M3 with the same conventions as in $\boldsymbol{A}$ and $\boldsymbol{B}$. See main text for a more detailed description.

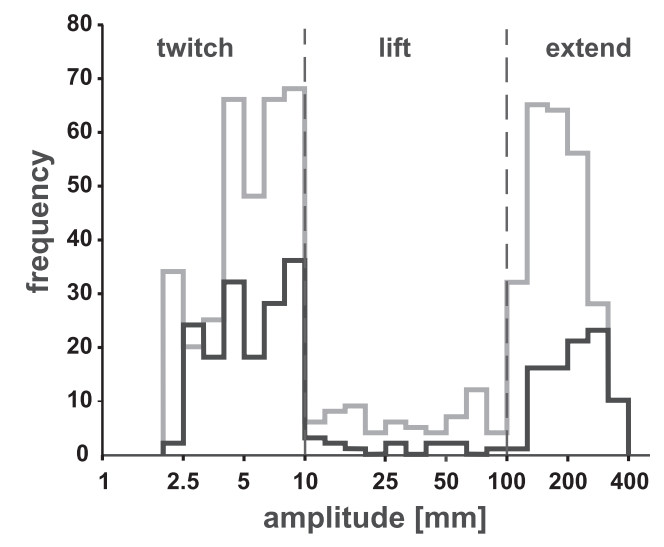

Figure 3. Amplitudes of elicited arm movements. Amplitudes are plotted logarithmically for the pretraining and posttraining period as black and gray histograms, respectively. Movements with amplitudes $<10 \mathrm{~mm}$ were defined as "twitch," between 10 and $100 \mathrm{~mm}$ as "lift," and larger than $100 \mathrm{~mm}$ as "extend" movements (separated by the vertical dashed lines).

2, $B$ and $D$. Generally, extend movements of monkeys M1 and M2 (data not shown) were more stereotypical; during one experiment at a particular stimulation site, the elicited extend movements were usually directed to the screen (Fig. 2B) or they stopped short of the screen (data not shown). Arm movements from monkey M3 before the training were much more erratic compared with those of monkeys M1 and M2. As shown in Figure $2 D$, most of M3's extend movements ended at the mouthpiece of the water tube (position 1), the upper right edge of the primate chair near the head (position 2), at the screen in front of the animal (position 3), or short of the screen in front of the monkey. The latter movements were often redirected to the initial position and therefore describe loop-like trajectories. After the training, M3's extend movements were more similar to those of M1 and M2. A quantitative comparison will be given in the next sections.

\section{Frequency of different types of arm movements}

To investigate whether training affects the frequency and quality of different electrically elicited arm movements in monkey M3, movements were plotted for each penetration versus consecutive experimental days. The probability to elicit an arm movement at all by electrical microstimulation was the same before and after the arm movement training ( $p>0.05$, Mann-Whitney $U$ test). The percentages for movement types twitch, lift, and extend relative to the total number of microstimulations applied are shown in Figure $4 A$. There was no obvious relation between experimental day and the frequency of different arm movement types (lack of linear regression for twitch, lift, or extend; $R$-values $<0.4, p>$ 0.05 ; note that between day eight and day 170 , the monkey was trained in different arm movement paradigms). Altogether, 18 penetrations (five before and 13 after the arm movement training) were taken into account.

The relative frequencies of successful microstimulations before and after the arm movement training of monkey M3 are plotted separately for each movement type for the contralateral arm in Figure $4 B$. Twitch movements characterized by small vertical deflections or the supination of the wrist were usually observed when the arm was calmly lying on the waist plate of the 
primate chair or when the monkey was holding the mouthpiece of the water tube. These twitch movements occurred in $56.2 \%$ and $49.5 \%$, whereas extend movements were observed in $37.0 \%$ and $38.7 \%$ of the successful trials before and after arm movement training, respectively. Lift movements of the hand, arm, or shoulder (5.5\% before and 10\% after training) were much less frequent. Therefore, comparing the frequencies for each movement type in monkey M3 before and after the arm movement training revealed that twitch and lift differ significantly with a lower probability for twitch and a higher probability for lift movements after the arm movement training $(Z$ test: $Z>1.6, p<$ $0.05)$. No difference was found for extend movements ( $Z$ test: $Z<1.6, p>0.05$ ).

So far, we considered extend movements as a single group. In the following, one subpopulation of arm movements that ended on the screen $\left(\operatorname{extend}_{S}\right)$, and therefore resembled the trained movements to a visual target on the screen, was distinguished from the remaining movements $\left(\right.$ extend $\mathrm{d}_{R}$ ), which stopped short of the screen or were directed at other locations such as the water tube or primate chair. Importantly, fully extended movements to the screen appeared significantly more often after monkey M3 was trained to reach to visual targets on the screen (4\% before training vs $9 \%$ after training; hatched areas in Fig. 4B; Yates corrected $\chi^{2}$ test: $p<0.05, \chi^{2}$ : 5.26, degrees of freedom: 1 ). Taking only extend movements into account, $10 \%$ were directed to the screen before and $22 \%$ after the training.

Twitch movements of the contralateral arm were the most common in monkey M2 (73\%) and in monkey M3 (49.5 after training). It is important to mention the frequent time-locked activation of the thumb (contralateral and ipsilateral to the stimulation site), which moved in a stereotypical manner even when all remaining parts of the limb were totally motionless. In contrast, the number of lift movements was much lower in M2 (1.8\%) compared with M3 (10\% after training). Electrical microstimulation successfully elicited extend movements of the contralateral arm in $25 \%$ of the effective trials in M2 (Fig. 8). It is noteworthy that the ratio of extend movements ending on the screen is comparable between monkey M3 and M2 ( 10\% across all elicited movement types, compare the dashed bars in Figs. $4 B$, $8)$. In the highly trained monkey M1, $30 \%$ of the arm movements were directed to the screen $\left(\right.$ extend $\left._{S}\right)$. Most of the remaining were extend $\mathrm{d}_{R}$ movements falling short of the screen.

In addition to arm movements, the monkeys showed movements of the eyes, head, and pinnae. Movements of the headespecially with stimulation in the posterior part of the SC-were accompanied by whole-body-turns into the direction contralateral to the stimulated SC. The monkey literally tried to take a look behind his back. Microstimulation applied in short succession turned the monkey step by step into the contralateral direction. At the deepest stimulation sites, the monkey started to lift the upper lip. When this moderate lifting of the lip changed into grimacing (particularly with electrode positions in the lateral half of the SC) or defensive-like movements, electrical microstimulation was stopped.
B

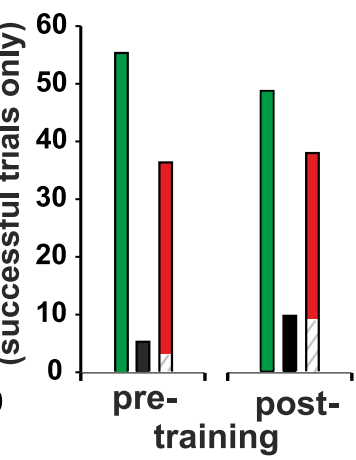

experimental day

training

Figure 4. A, Relative frequencies of different arm movements over experimental days. Success rates to elicit movement types itch" (green dots), "lift" (black dots) and "extend" (red triangles) are plotted for each experimental day for monkey M3. Al warm movements to visual targets. $\boldsymbol{B}$, Comparison of the average frequencies of successfully elicited twitch, trials in which electrical microstimulation elicited arm movements were included in the comparison. Hatched areas represent the

\section{Comparison of extend movement speed profiles between subjects and conditions}

The two different subgroups of electrically evoked extend movements $\left(\right.$ extend $_{S}$ and extend ${ }_{R}$ ) were analyzed in more detail and compared with goal-directed arm movements to visual targets conducted during the SR task.

Figure $5 \mathrm{~A}$ shows the speed profiles of electrically elicited extend movements directed to the screen for monkey M3 before (green, $n=7$ ) and after (gray and red, respectively; $n=57$ ) the arm movement training. After training, at least one-third of the speed profiles showed a saddle before the actual maximum (red curves). This decrease in speed precedes an additional submovement and was rarely observed before the reach training. The maximum speed of this submovement with $<0.85 \mathrm{~m} / \mathrm{s}$ (median: 0.68 $\mathrm{m} / \mathrm{s}$ ) is considerably lower than those represented by the bellshaped profiles (gray lines) recorded during the posttraining period. The latter in turn resemble the speed profiles of reach movements to visual targets on the screen recorded in the posttraining SR task (Fig. 5B). To gain representative data for the SR task, movements to three different targets at the screen (Fig. 1) were collected over 10 experimental days, pooled, and used for the analysis. These goal-directed movements exhibit exclusively bell-shaped speed profiles and show therefore constant kinetic properties over all experimental days (compare screen-directed with goal-directed movements in Fig. $5 A, B$, respectively). Therefore, pretraining profiles of electrically elicited arm movements to the screen have significantly lower maximum speeds and less stereotypically bell-shaped profiles and thus differ fundamentally from most profiles obtained by electrical microstimulation after the training and the visually guided arm movements recorded during the SR task.

Electrically elicited arm movements directed to the screen are characterized by significantly lower maximum speeds before than after the arm movement training $(0.69 \mathrm{~m} / \mathrm{s}$ vs $0.97 \mathrm{~m} / \mathrm{s}$, respectively, $p<0.01$; Fig. 6 , Table 1$)$. However, the median times to maximum speed do not differ significantly $(p>0.05)$.

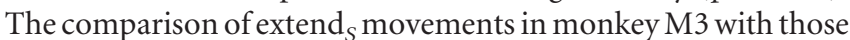
obtained during the SR task reveals no significant differences regarding maximum speed $(0.97 \mathrm{vs} 0.87 \mathrm{~m} / \mathrm{s})$ and time to maximum speed (154 vs $143 \mathrm{~ms}$ ). However, the same analysis for 


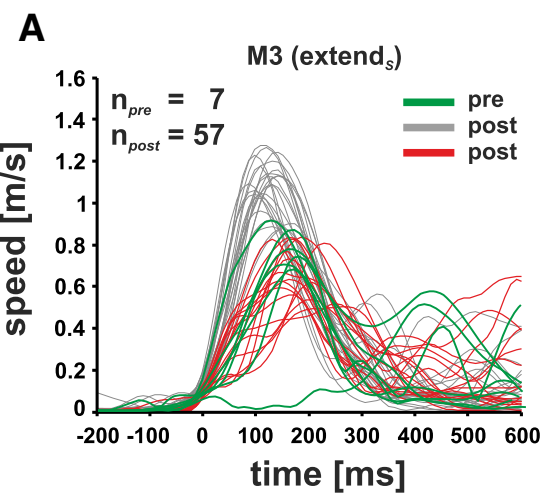

B

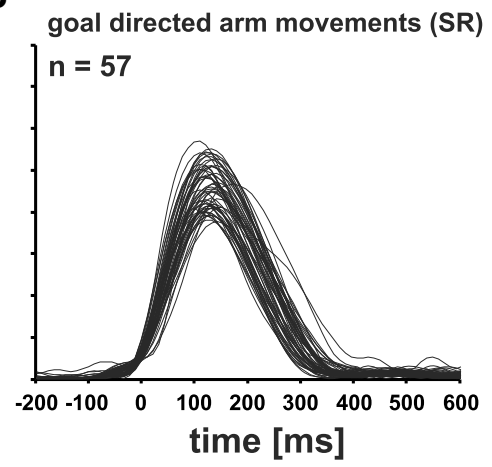

Figure 5. Speed profiles of "extend" arm movement of monkey $\mathrm{M} 3(\mathrm{~m} / \mathrm{s})$ over time $(\mathrm{ms})$ obtained during electrical microstimulation $(\boldsymbol{A})$ and during a standard SR task $(\boldsymbol{B})$. $\boldsymbol{A}$, Speed profiles of extend $\mathrm{d}_{\mathrm{s}}$ arm movements recorded before (green) and after the arm movement training (gray and red). Gray, Typical bell-shaped speed profiles of screen-directed arm movements; red, speed profiles with a plateau before the actual maximum speed (visible in at least one-third of screen-directed movements). $\boldsymbol{B}$, Speed profiles of goal-directed arm movements to visual targets recorded during the SR task. All speed profiles are aligned to movement onset.

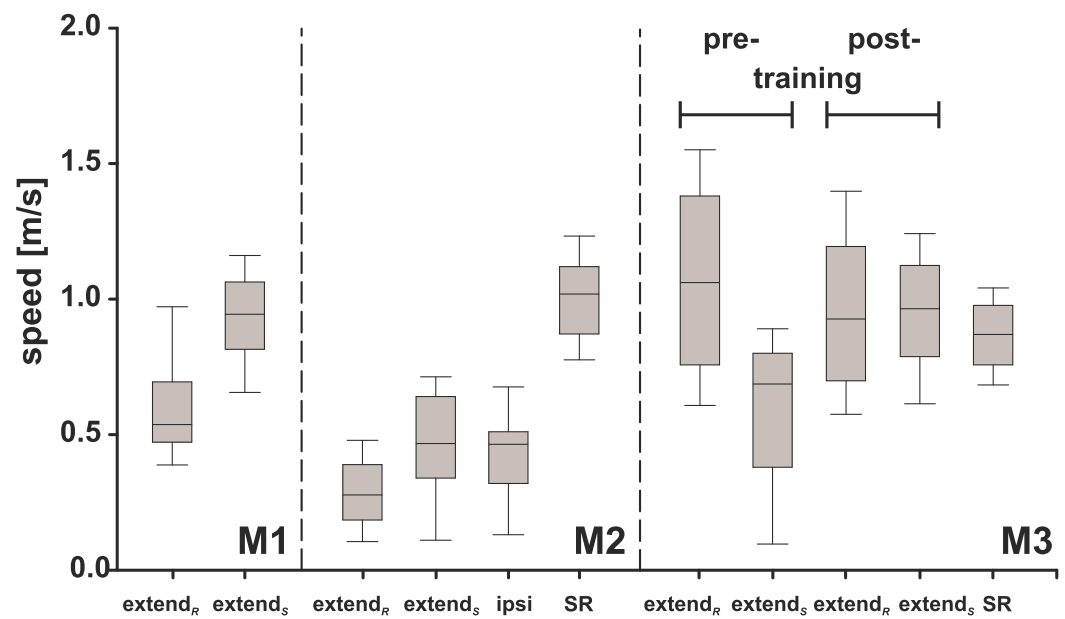

Figure 6. Box-and-whiskers plot of the maximum speeds of extend arm movements. The box signifies the first and third quartiles; the median is represented by the second quartiles within each box. Whiskers represent the 5 th and 95 th percentiles. For M2, maximum speeds of movements of the arm ipsilateral to the stimulated SC and maximum speeds for reaches in the SR task are also shown. For M3, the pretraining and posttraining arm movement speeds and the speeds of reaches in the SR task are shown separately. Consult Table 1 for median speeds.

monkey M2 reveals significantly slower speeds and longer times to maximum speed for electrically elicited movements to the screen compared with those obtained during the SR task ( $0.47 \mathrm{vs}$ $0.97 \mathrm{~m} / \mathrm{s}$ and $467 \mathrm{vs} 131.9 \mathrm{~ms}$, respectively; $p<0.001$ ). This, together with the same albeit not significant tendency in monkey M3, shows that the two movements (electrically induced and SR) can differ substantially from each other. This does not hold true for the remaining population of extend $\mathrm{R}_{R}$ movements. These movements are mainly directed to a position located at the top of the primate chair, the water tube of the reward system, or an undefined position in front of the monkey (Fig. 2D) and are characterized by longer trajectories and the lack of a distinct endpoint (e.g., the screen).

Maximum speeds of extend ${ }_{R}$ arm movements of monkey M3 were higher before the arm movement training than afterward $(1.1 \mathrm{~m} / \mathrm{s}$ vs $0.93 \mathrm{~m} / \mathrm{s}, p<0.01)$, but the latter had still higher maximum speeds and longer times to maximum speed $(p<$ 0.001) than those obtained during the SR task (Table 1). The opposite can be observed for extend ${ }_{R}$ movements in monkey M2 (maximum speeds were significantly lower and times to maximum speed significantly longer compared with SR movements, $p<0.001)$. The maximum speeds in monkey M1 and M2 differed significantly between extend $\mathrm{S}_{S}$ and extend $\mathrm{d}_{R}$ (faster movement speeds for extend ${ }_{S}, p<0.001$ ). Monkey M3 exhibited the same, albeit not statistically significant, tendency (for all maximum speeds and times to maximum speed, see Table 1).

\section{Comparison of extend movement latencies between subjects and conditions}

The onset latencies of the three different movement types in monkey M3 were calculated before and after the arm movement training and compared with the latencies from M1 and M2. In general, twitch, lift, and extend onset latencies were significantly higher before the monkey was trained to execute arm movements to visual targets ( $p<0.001$, MannWhitney $U$ test; Table 2).

The histogram in Figure $7 A$ shows the onset latencies for extend ${ }_{S}$ movements before and after the arm movement training for monkey M3 (gray and black outlined histograms, respectively; triangles demarcate the corresponding median latencies). Altogether, 66 trials for monkey M3 (9 and 57 trials for the pre-arm-movement and post-arm-movement training period, respectively), 34 for monkey $\mathrm{M} 2$, and 81 for monkey M1 were taken into account (dark and light boxes, respectively). Latencies range from 45 to $740 \mathrm{~ms}$. The median onset latency of monkey M3 is significantly shorter than the median onset latency of monkey $\mathrm{M} 1$ and of monkey M2 ( $p<0.001$, Mann-Whitney $U$ test). Monkey M1 and M2 exhibited no significant differences in their onset latencies $(p>0.05)$. In subject M3, the pretraining and posttraining extend $\mathrm{s}_{\mathrm{S}}$ latencies differed significantly from each other $(p<0.05)$, with shorter onset latencies after the training. Interestingly, after training, extend $\mathrm{S}_{\mathrm{S}}$ arm movement latencies were significantly shorter than those after visual stimulation during the SR task (241.8 ms after stimulation onset vs $317.3 \mathrm{~ms}$ after visual stimulus onset; $p<0.001$; compare Fig. $7, A$ and $C$, Table 2). However, the opposite was true for monkey M2 (401.1 ms vs $314.3 \mathrm{~ms}$, respectively; $p<0.001$ ).

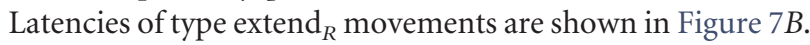
For monkey M3, 276 trials (78 and 198 trials for the pre-armmovement and post-arm-movement training period, respectively) were taken into account and, for monkeys M1 and M2, 190 and 85 trials were taken into account, respectively. Latencies range from 45 to $770 \mathrm{~ms}$. The difference between the pretraining and posttraining latencies in monkey M3 is highly significant $(p<0.001)$, with shorter onset latencies after training. An intraindividual comparison revealed that extend ${ }_{R}$ and extend $d_{S}$ type latencies do not differ significantly from each other $(p>0.05)$. The comparison of extend ${ }_{R}$ latencies with those obtained during the SR task reveals significantly shorter extend ${ }_{R}$ latencies for 
Table 1. Median values of maximum speeds, times to maximum speed, and latencies for electrically elicited extend arm movements of the contralateral arm for all three monkeys

\begin{tabular}{|c|c|c|c|c|}
\hline & $\begin{array}{l}\text { Maximum } \\
\text { speed }(\mathrm{m} / \mathrm{s})\end{array}$ & $\begin{array}{l}\text { Time to maximum } \\
\text { speed (ms) }\end{array}$ & $\begin{array}{l}\text { Latency } \\
\text { (ms) }\end{array}$ & $n$ \\
\hline \multicolumn{5}{|l|}{ Monkey M1 } \\
\hline Extend $_{s}$ & 0.94 & 153.9 & 417.6 & 81 \\
\hline Extend $_{R}$ & 0.54 & 98.9 & 428.6 & 190 \\
\hline \multicolumn{5}{|l|}{ Monkey M2 ${ }^{a}$} \\
\hline Extend $_{s}$ & 0.47 & 467.0 & 401.1 & 34 \\
\hline Extend $_{R}$ & 0.28 & 174.7 & 384.6 & 85 \\
\hline$S R$ & 0.97 & 131.9 & 314.3 & 85 \\
\hline \multicolumn{5}{|c|}{ Monkey M3 (pretraining) } \\
\hline Extend $_{S}$ & 0.69 & 157.8 & 318.7 & 9 \\
\hline Extend $_{R}$ & 1.1 & 164.8 & 252.8 & 78 \\
\hline \multicolumn{5}{|c|}{ Monkey M3 (posttraining) } \\
\hline Extend $_{S}$ & 0.97 & 153.9 & 241.8 & 57 \\
\hline Extend $_{R}$ & 0.93 & 164.8 & 208.8 & 198 \\
\hline SR & 0.87 & 142.9 & 317.3 & 57 \\
\hline \multicolumn{5}{|l|}{ Ipsilateral } \\
\hline Extend $_{R}$ & 0.46 & 461.5 & 373.6 & 13 \\
\hline
\end{tabular}

${ }^{a}$ For monkey M2, data from the ipsilaterally elicited arm movements are also shown.

Table 2. Median latencies and range of electrically elicited arm movements

\begin{tabular}{llll}
\hline Median latencies (ms) & Twitch & Lift & Extend $_{(\mathrm{R}+\mathrm{S})}$ \\
\hline Monkey M1 & - & - & $428.6(271)$ \\
$\quad$ Min-max & - & - & $44-747$ \\
Monkey M2 & $329.7(309)$ & $467(6)$ & $390.1(132)$ \\
$\quad$ Min - max & $44-945$ & $363-571$ & $44-956$ \\
Monkey M3 $^{a}$ & & & \\
$\quad$ Pretraining & $307.7(132)$ & $406.6(13)$ & $263.7(87)$ \\
Posttraining & $241.8(327)$ & $252.8(65)$ & $219.8(255)$ \\
Min-max, pretraining + posttraining & $55-736$ & $55-634$ & $44-692$ \\
$p$-value (pretraining vs posttraining) & $p<0.001$ & $p<0.001$ & $p<0.001$ \\
\hline
\end{tabular}

Numbers of measurements are shown in parentheses.

${ }^{a}$ For monkey M3, $p$-values from the Mann-Whitney $\mathrm{U}$ test for the comparison of the pretraining and posttraining latencies are shown.

monkey M3 but longer latencies for monkey M2 $(p<0.001)$. Trials with latencies longer than $800 \mathrm{~ms}(<1 \%)$ were discarded from the analysis.

Movements of the arm ipsilateral to the stimulated SC

The most commonly elicited movement type in the arm ipsilateral to the stimulated SC in monkey M2 were twitch movements (Fig. 8). Comparing the frequencies of twitch, lift, and extend movements elicited in the contralateral and ipsilateral arm revealed that twitch and extend differ significantly with a higher probability of twitch and a lower probability of extend movements of the ipsilateral arm $(Z$ test: $Z>3.1, p<0.001)$. No difference was found for lift movements $(Z$ test: $Z<1.6, p>$ 0.05).

Maximum speeds of twitch movements were significantly lower for the ipsilateral limb than those for the contralateral limb $(0.029 \mathrm{vs} 0.078 \mathrm{~m} / \mathrm{s}, p<0.001)$. However, latencies of ipsilaterally elicited twitch movements were significantly shorter compared with latencies of contralaterally elicited twitches ( 274.7 vs 329.7 $\mathrm{ms}, p<0.001)$. This can be explained by the fact that latencies of contralaterally elicited movements of the early experimental phase were also significantly longer than those of the late phase (428.6 vs $197.8 \mathrm{~ms}, p<0.05$ ). These latter contralateral latencies, in turn, did not differ significantly from latencies of the ipsilaterally elicited movements, which were mainly studied in the later phase of the experiments on M2. Electrical microstimulation also
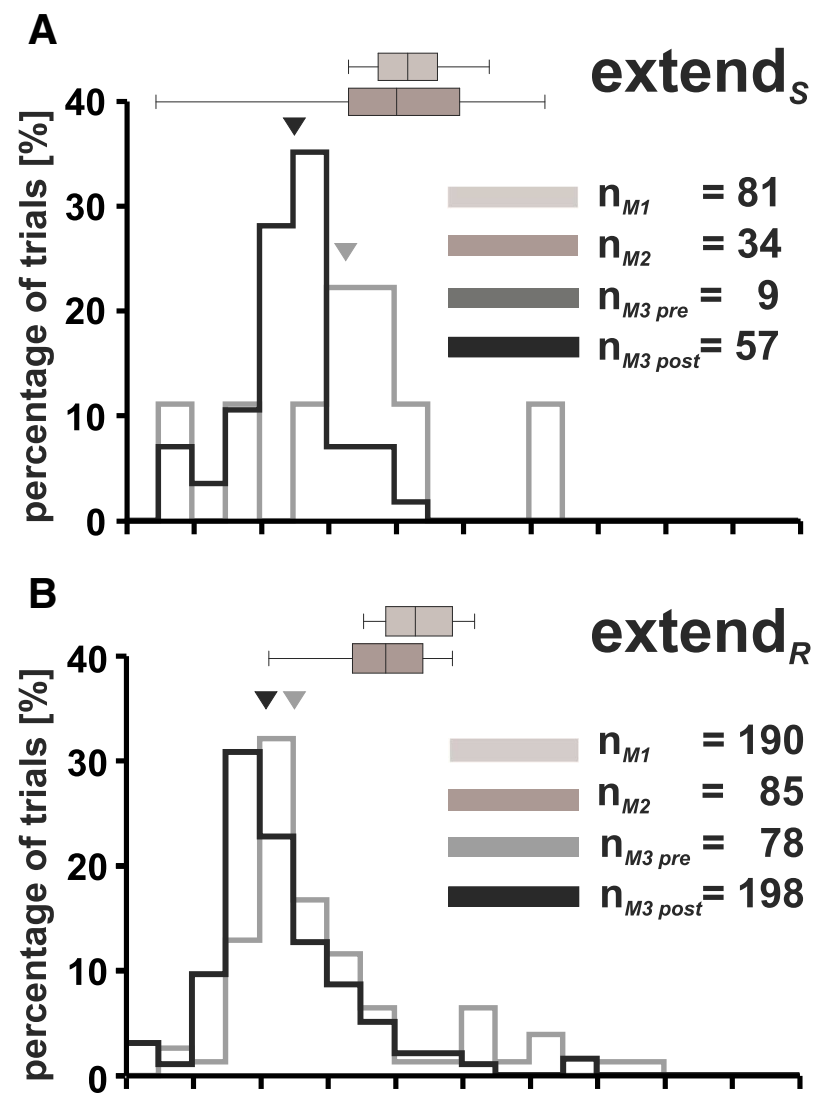

C

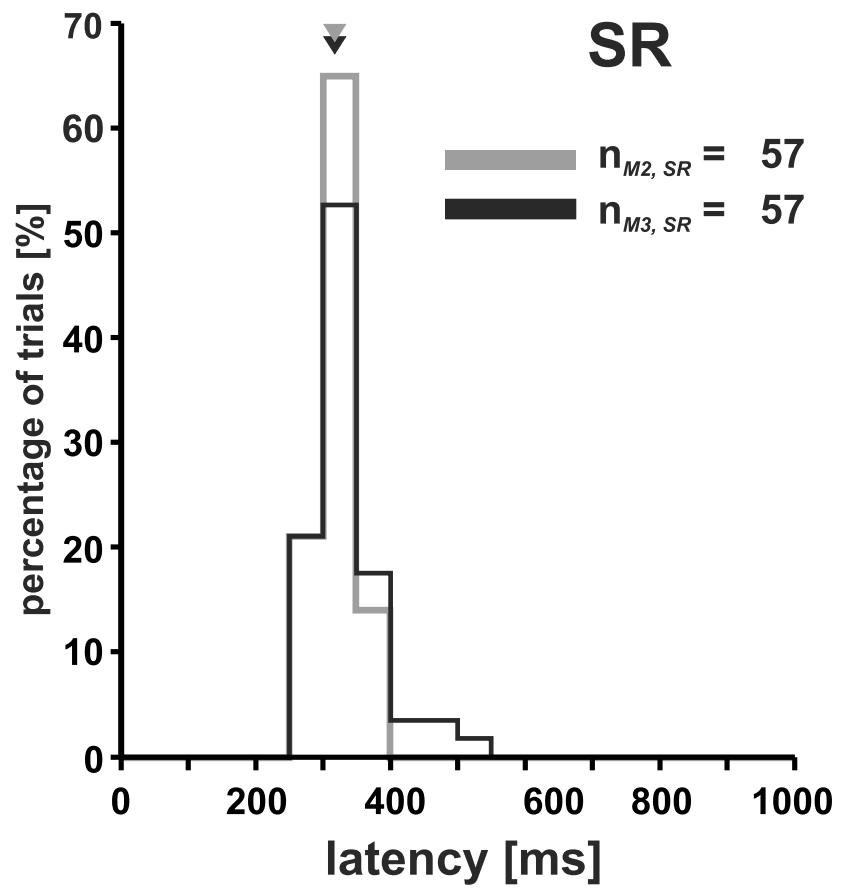

Figure 7. Latencies of extend arm movements. $\boldsymbol{A}, \boldsymbol{B}$, Latency distribution (ms) for arm movements elicited in monkey M3 for extend ${ }_{S}$ and extend ${ }_{R}$ movements (gray histogram, pre-armmovement training; black histogram, post-arm-movement training, 50 ms bins; corresponding triangles mark the median latencies). Latencies of monkey $\mathrm{M} 1$ and $\mathrm{M} 2$ are represented as horizontal boxplots (light and dark gray box, respectively) on top of the histograms (same conventions as in Fig. 6). C, Latencies of the SR task for monkey M2 and M3 (gray and black histogram, respectively; triangles mark median latencies). Consult Table 1 for median latencies. 


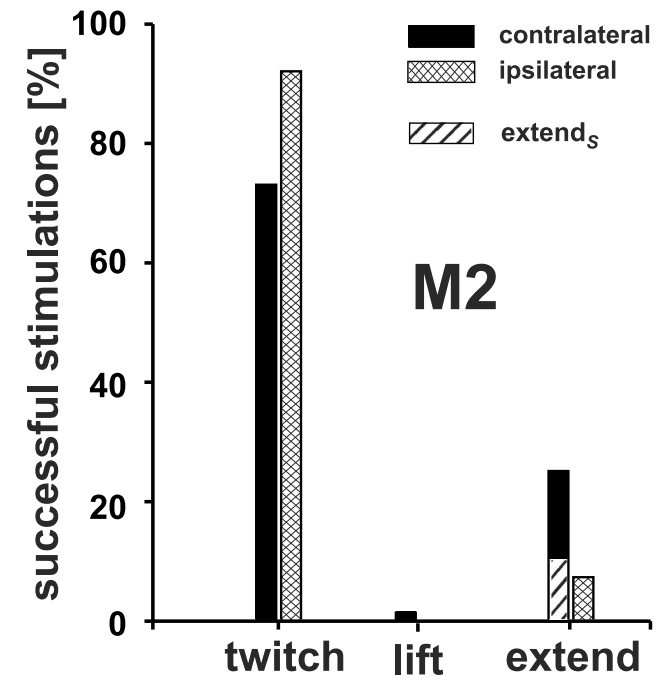

Figure 8. Relative frequencies of "twitch", "lift," and "extend" movements of both arms elicited by stimulation of one SC in monkey M2. Black and cross-hatched bars represent the frequencies of movements elicited in the arm contralateral and ipsilateral to the stimulated SC, respectively.

elicited extend movements in the ipsilateral arm, although less frequently than in the contralateral arm ( $7 \%$ vs $25 \%$ of the trials, respectively).

Maximum speeds of ipsilaterally elicited extend movements did not differ from extend ${ }_{S}$ movements of the contralateral arm $(p>0.05)$, but were significantly faster than contralateral extend $\mathrm{d}_{R}$ movements $(p<0.01)$. The ipsilaterally elicited extend movements in monkey M2 did not differ in terms of their latencies from the contralaterally elicited extend $\mathrm{d}_{S}$ or extend $\mathrm{d}_{R}$ movements $(p>0.05)$. Microstimulation in M3 during the posttraining period elicited movements of the ipsilateral arm as well at all nine sites tested, thus confirming the results from M2. The same movements as those of the contralateral arm (especially twitches of the arm or wrist) were observed. However, these movements were usually less pronounced than those elicited in the contralateral arm from the same site. Interestingly, while probing the ipsilateral arm, conspicuous extend movements to the screen were observed neither in monkey M2 nor in M3.

\section{Topographic distribution of electrically elicited arm movements}

For the topographic analysis, penetrations effective to elicit arm movements in monkey M2 (green and red dots) and M3 (black dots) are plotted in Figure 9 in collicular coordinates on the visuomotor map with the origin demarcating the rostral pole of the SC (Ottes et al., 1986). Electrical microstimulation in a relatively narrow band within the lateral half of the SC along the $-45^{\circ}$ isodirection line was particularly effective in eliciting arm movements,. Relative frequencies of twitch and lift movements together are shown in Figure $9 A$, of extend movements in Figure 9, $B$ and $C$, and of thumb only movements in Figure 9D. The size of the circles in Figure 9, $A-C$, indicates the relative frequency of the different arm movement types with respect to all effective microstimulations in a certain penetration. Importantly, reach movements directed exclusively to the screen (Fig. 9C) could be elicited from the same stimulation sites as the remaining movements. The same was true for thumb movements induced in M2 and M3 plotted in Figure 9D. For monkey M2, ipsilaterally elicited arm movements are additionally plotted as red circles and dots in Figure 9, $A$ and $B$. Blue crosses and dots symbolize penetrations in which electrical microstimulation did not elicit any arm movements at all in monkey M2 and M3, respectively. However, other effects, such as eye, ear, or head movements, could sometimes be observed.

The dots in the same location in Figure 9, $A-D$, represent the same penetration. By close inspection, it becomes clear that, within almost all penetrations, more than one type of movement (if not all) could be elicited. A crucial question remains: what is the distribution of movements evoked from the same stimulation site along the penetrations? It became evident during the experiments that often more than one movement type could be elicited from a given stimulation site, keeping the stimulation parameters identical. Of course, the threshold and by that the set stimulus current varied from site to site. To quantify this observation, we calculated an index (see Materials and Methods) for each stimulation site and plotted it versus depth or current strength in the SC for monkeys M2 and M3 in Figure 10, $A$ and B. A dot with a value of -1 represents a site at which only twitch and lift could be elicited, a dot with a value of +1 a site at which only extend movements could be elicited, and a dot with a value of 0 a site at which both movement types could be elicited equally effectively. As can be seen in Figure 10A, sites show various combinations of preferences for certain movements at all depths. The histogram on the right depicts the frequency distribution of the various combinations. Sites from which only twitch and lift movements could be elicited are the most numerous. Sites more effective for twitch and lift (lower dots) outnumber sites more effective for extend movements (dots above horizontal line) by 2:1. We also analyzed the influence of different strengths of stimulation current across all stimulation sites and at four individual sites (Fig. $10 B)$. The effects of different current strength at the four individual sites are ambiguous (identical letters refer to the same stimulation site). Taking all stimulation sites into account also does not reveal a clear relationship between the strength of stimulation current and movement type. However, a simple regression indicates a trend for a decreased probability of extend movements at higher currents $(p<0.05)$. Taking the information presented in Figures 9 and 10 together, it becomes clear that sites from where given arm movement types or a combination of them could be elicited are spread out fairly evenly in the lateral part of the SC over a depth range from 1.5 to $4.5 \mathrm{~mm}$ below its surface.

\section{Depth dependency of the frequency of electrically elicited arm movements}

Effective depths in the SC to elicit arm movements by microstimulation range from 1460 to $3500 \mu \mathrm{m}$ in the overtrained monkey M1, from 1900 to $5100 \mu \mathrm{m}$ in monkey M2, and from 1400 to $4600 \mu \mathrm{m}$ below SC surface in monkey M3 (Figs. 10, 11). The more lateral and posterior the penetration sites were located, the more superficially could arm movements be elicited (linear regression $r=0.25, p<0.05$ and $r=0.49, p<0.001$ for mediolateral and rostrocaudal regression, respectively). For the linear regressions, all effective depths were plotted versus the location in collicular coordinates only for monkey M3 because the SC was mapped most evenly in this animal.

To reveal a possible depth dependency for effective microstimulations in a given penetration, the depth distribution was analyzed in more detail. The median depths for effective microstimulation sites in the pretraining and posttraining period of monkey M3 do not differ significantly (naive: $n=25,3820$ 
$\mu \mathrm{m}$; subsequently trained: $n=55,3475$ $\mu \mathrm{m} ; p>0.05$, Mann-Whitney $U$ test) and are therefore pooled for further analysis (median depth: $3650 \mu \mathrm{m}$, black triangle in Fig. 10). The comparison between M2 ( $n=40,3900 \mu \mathrm{m}$; contralateral and ipsilateral data are pooled) and M3 revealed a slight but significantly stronger bias for deeper sites to be effective in M2 $(p<0.05)$. However, comparing only the deeper depths of the bimodal distribution in monkey M3 with those of monkey M2 does not show a significant difference $(p>0.05)$. Median depths for the overtrained monkey M1 $(n=16,2150 \mu \mathrm{m})$ differ significantly from M3 and M2 $(p<0.001$, Mann-Whitney $U$ test). Thumb movements could be elicited in M2 and M3 at depths ranging from 2660 to $4500 \mu \mathrm{m}$.

As already mentioned, the depth distribution is not unimodal but shows two peaks around 1900 and $3900 \mu \mathrm{m}$ in monkey M3. However, most of the arm movements were elicited in the deeper layers of the SC (Fig. 11D, black triangle). Importantly, effective stimulation sites were found in both depth ranges in the same penetrations. At 21 sites in M3 ( 4 of 25 tested before and 17 of 55 after the reach training, respectively), stimulation at depths $>2600 \mu \mathrm{m}$ (minimum depths are 1900 and $1400 \mu \mathrm{m}$ for the pretraining and posttraining period, respectively) elicited arm movements. No arm movements at all could be elicited in depths ranging from 500 to $1400 \mu \mathrm{m}$, $2200-2600 \mu \mathrm{m}$, or 4600 to $5700 \mu \mathrm{m}$ regardless of how high an electrical current was chosen (median current strength: $25 \mu \mathrm{A}, 25$ th: $20 \mu \mathrm{A}$, 75th: 30 $\mu \mathrm{A}$; maximum current strength: 50 $\mu \mathrm{A})$. A comparison of effective stimulation sites $>2600 \mu \mathrm{m}$ with those $<2600$ $\mu \mathrm{m}$ revealed that these two populations differ significantly from each other with higher success rates for deeper stimulation sites (55\% vs $65 \%$, respectively; $p<$ 0.05 , Mann-Whitney $U$ test). In monkey M2, only 3 of 30 stimulation sites were effective at $<2600 \mu \mathrm{m}$. Even if there was no bimodal distribution in $\mathrm{M} 2$, the frequency of successful stimulations increased with depth in the SC. Therefore, microstimulation experiments in these two monkeys were most successful at sites probed deeper than $2600 \mu \mathrm{m}$ below the SC surface. However, in the overtrained monkey M1, the majority of microstimulation experiments (13 of 16) were successful, mostly eliciting extend movements already at depths $<2600 \mu \mathrm{m}$ (minimum depth: $1460 \mu \mathrm{m}$ ). This raises the interesting question of whether in M2 and M3 extend movements to the screen can be elicited more often from superficial stimulation sites, a result supporting the hypothesis that arm movements were triggered mostly by phosphenes or
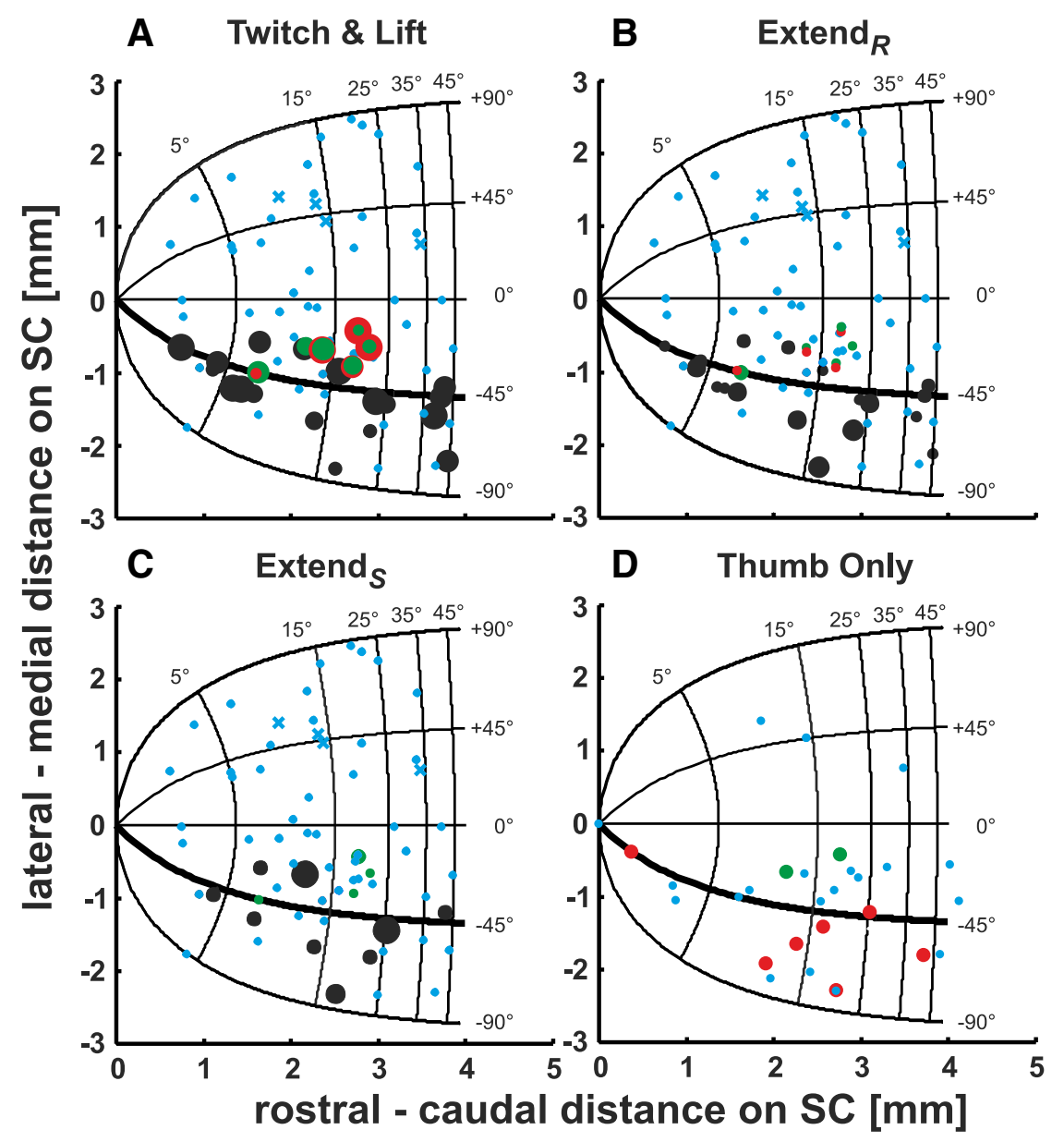

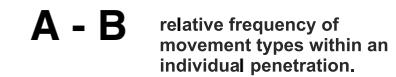

$\begin{array}{r}81 \%-100 \% \\ \hline \quad 61 \%-80 \% \\ \hline \quad 21 \%-60 \% \\ \hline \\ \hline\end{array}$
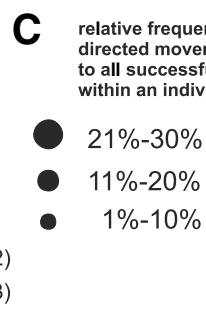

D penetration sites,

Distribution of relative frequencies of successful microstimulations plotted on the collicular motor map. The collicular oculomotor map (degree) is presented in Cartesian coordinates $(\mathrm{mm})$, with its origin representing the rostral pole of the SC. Iso-amplitude lines are running vertically in mediolateral direction and isodirectional lines horizontally in rostrocaudal direction. Black dots represent penetrations where arm movements could be elicited in M3; green and red dots correspond to penetration of the movement type with respect to all successful microstimulations within the corresponding penetration (see bottom of figure). Blue crosses and dots demarcate ineffective microstimulation sites in monkey $M 2$ and M3, respectively. D, Green and red dots correspond to locations where thumb movements could be elicited in M2 and M3, respectively.

changes in saliency caused by the microstimulation in the intermediate layers. This was clearly not the case. Of the stimulation sites down to $2600 \mu \mathrm{m}$ below the SC surface, only $3.6 \%$ led to extend movements to the screen, whereas at $>2600 \mu \mathrm{m}$, it was $7.9 \%$.

Ipsilateral arm movements in M2 were exclusively elicited at sites ranging from 2800 to $4600 \mu \mathrm{m}$ below the SC surface (Fig. 11C). Median depths for contralaterally and ipsilaterally elicited arm movements in monkey M2 did not differ (3980 and $4000 \mu \mathrm{m}$, respectively; median current strength: $30 \mu \mathrm{A}$, 25th: $21 \mu \mathrm{A}$, 75th: $35 \mu \mathrm{A}$; maximum current strength: $37 \mu \mathrm{A}$ ). Movements of the arm ipsilateral to the stimulated SC were 
A

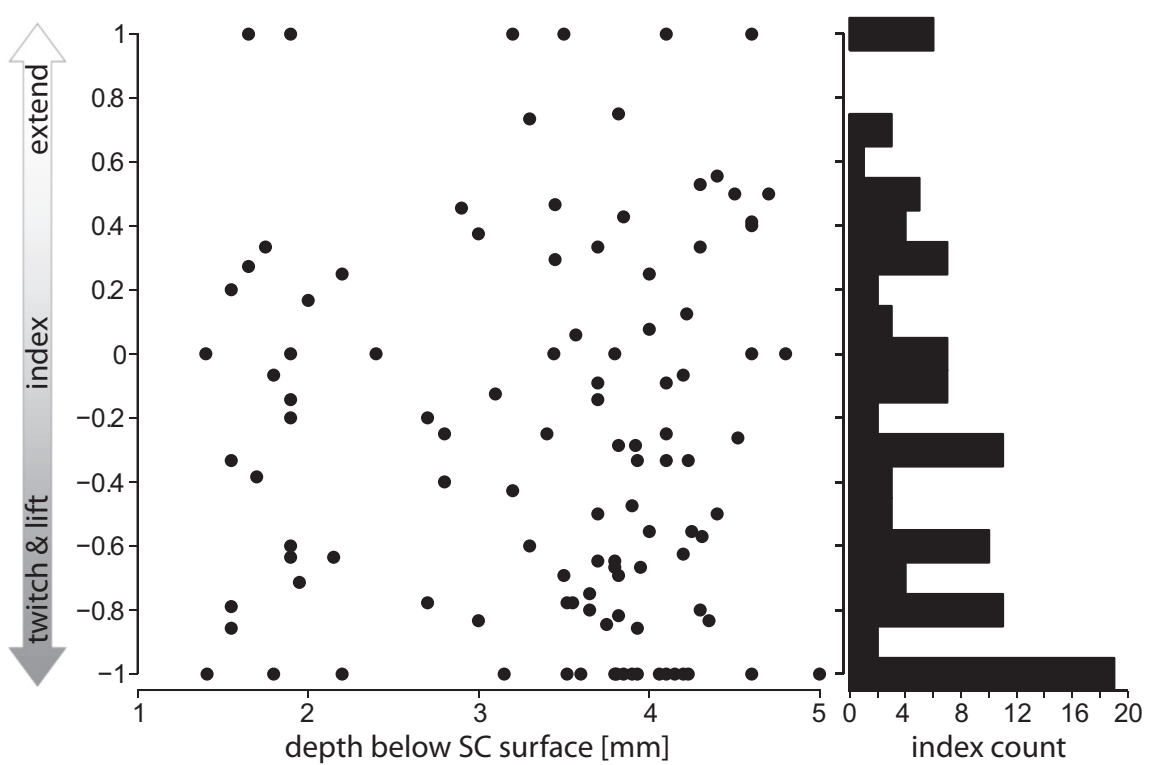

B

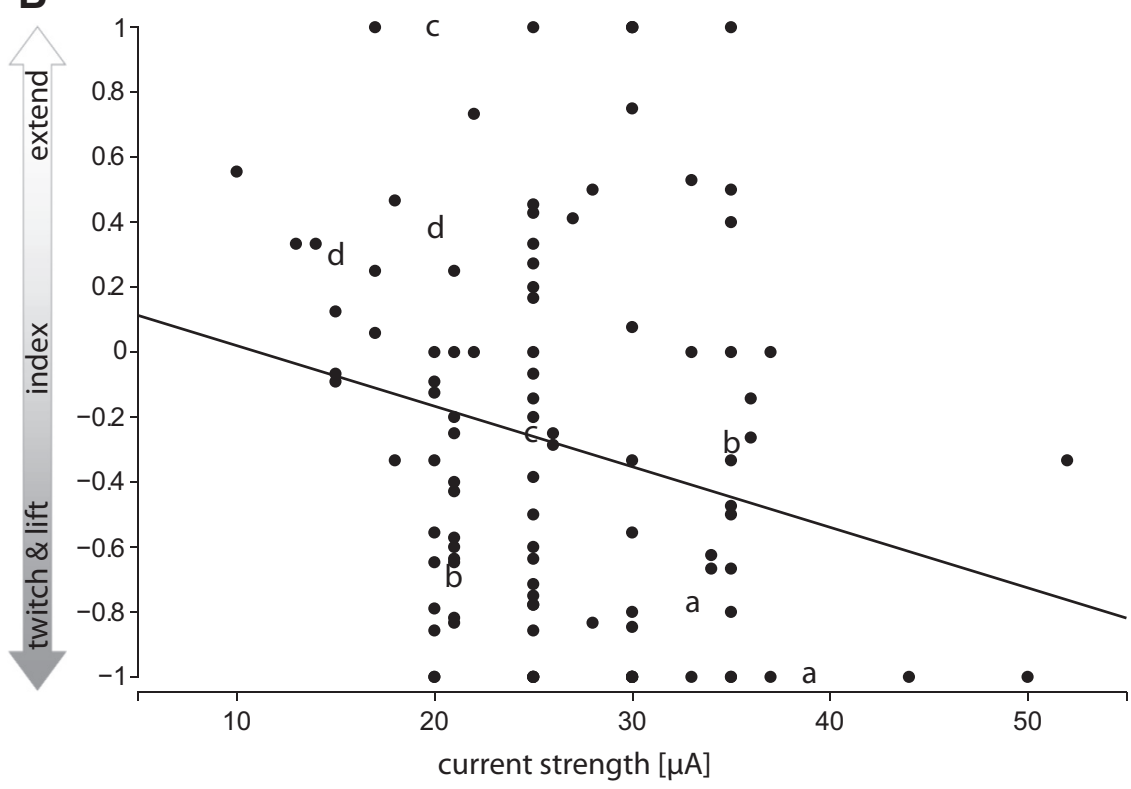

Figure 10. A, Depth distribution of an index specifying the ratio between the frequencies of twitch and lift and of extend movements elicited by electrical microstimulation at the same stimulation site in the superior colliculus. $y$-axis, Twitch and lift or extend index; $-1=$ only twitch and lift; $+1=$ only extend movements; $0=$ twitch and lift and extend movements with equal probability. Left $x$-axis, Depth below surface of the $S C$; right $x$-axis, frequency of indices in 0.1 bins. $B$, Influence of microstimulation current strength (plotted along the $x$-axis) on the likelyhood to elicit twitch and lift or extend movements (index as specified in $A$ plotted along the $y$-axis). Letters indicate four examples with two different current strengths applied at the same stimulation site.

also elicited in monkey M3. The depth distribution (not plotted because of a too small sample) was similar to M2, ranging from 2700 to $4600 \mu \mathrm{m}$ (median depth: $3100 \mu \mathrm{m}$ ).

\section{Topographic distribution of the latencies of electrically} elicited arm movements

Response latencies of extend movements elicited in monkey M3 are projected onto the SC motor map shown in Figure 12A (open and filled black dots demarcate values before and after arm movement training, respectively). Shorter latencies are marked by the bigger dots, longer latencies by the smaller dots. No significant correlation between the median onset latencies and the medio- lateral or rostrocaudal location of the stimulation sites was found $(r=0.357$, $p>0.05$ and $r=0.061, p>0.05$, respectively). Green and red dots correspond to response latencies recorded in monkey M2 for contralaterally and ipsilaterally elicited arm movements, respectively.

The posttraining latencies of extend movements elicited in monkey M3 (black dots) and M2 (contralateral: gray crosses, ipsilateral: open black circles) were plotted versus depth below SC surface in Figure $12 B$. Dividing the latencies into a superficial $(<2200 \mu \mathrm{m})$ and a deep population $(>2600 \mu \mathrm{m})$ and comparing the median latencies reveals a clear preponderance for shorter latencies at deeper stimulation sites (296.7 $\mathrm{ms}$ for the superficial vs $241.8 \mathrm{~ms}$ for the deep population; $p<0.001$; MannWhitney $U$ test; data from $\mathrm{M} 2$ and $\mathrm{M} 3$ were pooled, see box plots in Fig. 12B). Most notably, latencies $<150 \mathrm{~ms}$ were found only at depths $>2600 \mu \mathrm{m}$, with one exception in M2. Therefore, electrical microstimulation is more effective and leads to responses at shorter latencies if applied in the deep collicular layers and underlying reticular formation than in the superficial or intermediate layers.

\section{Discussion}

Our experiments show clearly that electrical microstimulation in the intermediate and deep layers of the macaque monkey's SC is able to elicit twitch, lift, and extend arm movements. Onset latencies of twitch and extend movements do not differ (range: 45$770 \mathrm{~ms}$ ). Most successful microstimulations were restricted to the lateral SC along the $-45^{\circ}$ isodirection line of the retinotopic map. Here, at a depth of $2800-4800 \mu \mathrm{m}$ below the SC surface, microstimulation evoked many arm movements with short latencies ( $<200 \mathrm{~ms}$ ) comparable to latencies of head movements (Freedman et al., 1996). The mechanical load in the skeletomotor system creates the perception of such long latencies, a limitation that could be circumvented by quantifying the latency of stimulation-evoked changes in EMG activity of neck and arm muscles (Corneil et al., 2002).

Neuronal substrate for arm movements electrically evoked from the superior colliculus

Our stimulation duration covers the collicular neural activity before and during reaches (Werner et al., 1997a), which precedes the tightly correlated EMG activity in arm muscles (Stuphorn et al., 1999). Therefore, in analogy to motor cortex, microstimulation in the SC could cause arm movements with short latency by an at least disynaptic projection to motoneurons in the spinal cord. 


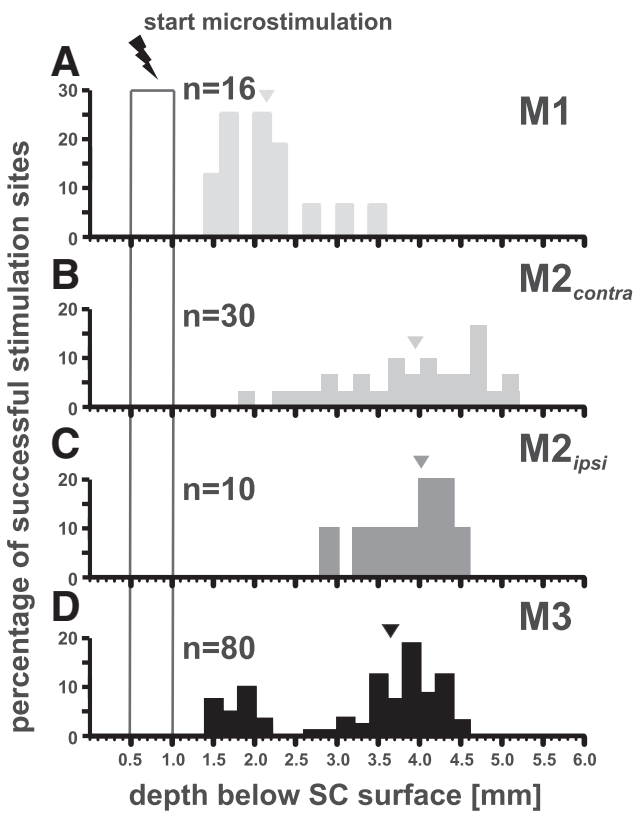

Figure 11. Histograms showing the percentage of effective microstimulation sites $(200 \mu \mathrm{m}$ bins) plotted versus depth $(\mathrm{mm})$ below the collicular surface for monkey M1 ( $A$, light gray); for monkey M2 [contralaterally vs ispsilaterally elicited arm movements in gray $(\boldsymbol{B})$ and dark gray $(\boldsymbol{C}$, respectively], and for monkey $\mathrm{M} 3$ in black $(\boldsymbol{D})$. Triangles represent the median depths of effective stimulation sites (M1: $2150 \mu \mathrm{m}$; M2, contralateral: $3980 \mu \mathrm{m}$, ipsilateral: $4000 \mu \mathrm{m}$; M3: $3650 \mu \mathrm{m})$. Open rectangle from 0.5 to $1 \mathrm{~mm}$ represents the depth range where electrical probing started.

In monkey, the majority of tecto-spinal neurons (TSNs) are found in small groups within the stratum griseum profundum and stratum griseum intermediale of the posterior and lateral part of SC (Castiglioni et al., 1978; Nudo et al., 1993; Robinson et al., 1994). A population of intermediate and deep collicular neurons possesses bilateral and reciprocal connections with the underlying central mesencephalic reticular formation. This structure in turn sends descending fibers to the ipsilateral spinal cord and receives ascending projections from the same site (Horn, 2006; May, 2006). This projection of reticulospinal neurons could explain our observation that electrical microstimulation in the SC causes also twitches of the arm or wrist ipsilateral to the stimulation site. In fact, Werner et al. (1997a) described reach related activity of collicular neurons also during the use of the ipsilateral arm. Possibly, the SC has not only access to the upper cervical segments (C1-C3), but disynaptically via the brainstem or via propriospinal neurons also to more caudal segments dealing with the control of more distal limb muscles (Grillner and Lund, 1968; Peterson et al., 1979). This is consistent with our results showing that bilateral movements of the thumb and supination of the wrist were elicited in a regular manner. Stimulation in the pontomedullary reticular formation (PMRF) evokes ipsilateral limb flexor and contralateral limb extensor muscle excitation sometimes accompanied by a reciprocal suppression of the antagonistic muscles. The PMRF is therefore not only involved in the control of locomotion (Matsuyama et al., 2004) and postural support during reaching movements (Schepens et al., 2008), but also in voluntary reaching (Buford and Davidson, 2004), and is thus in a position to relay reach related tectal output to arm muscles (Davidson and Buford, 2004). These findings and the short latencies presented in the present study could explain the presence of rapid arm muscle activity ( $<100 \mathrm{~ms}$ latency) that was
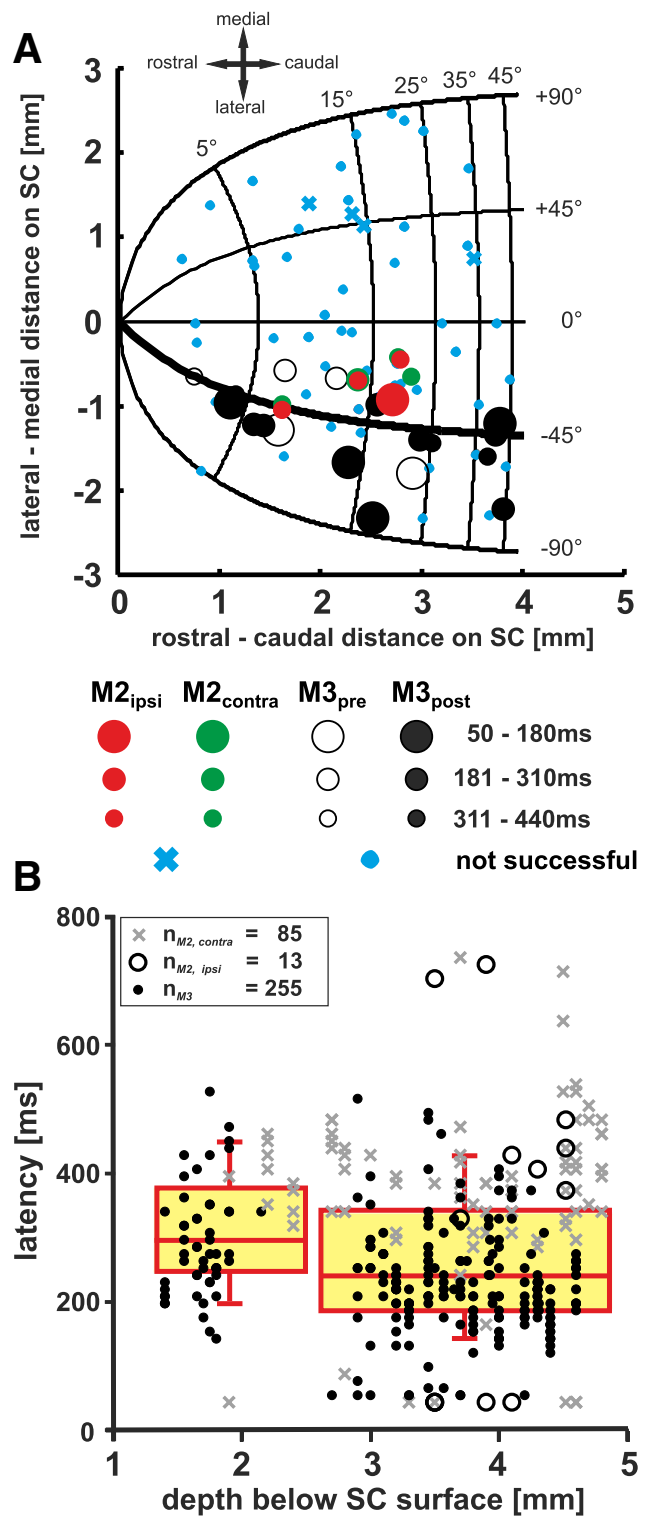

Figure 12. $\quad \boldsymbol{A}$, Response latencies of extend movements (ms) before and after the arm movement training for monkey $\mathrm{M} 3$ (open circles and black dots, respectively). Response latencies of monkey $\mathrm{M} 2$ are shown in green and red dots for contralateral and ipsilateral arm movements, respectively. Blue crosses and dots demarcate unsuccessful penetration sites (monkey M2 and M3, respectively). Larger circles indicate shorter latencies (see panel between $\boldsymbol{A}$ and $\boldsymbol{B}$ ). $\boldsymbol{B}$, Single trial "extend" latencies (ms) of monkey M2 and M3 (in the post-arm-movement training period) plotted against depth below SC surface $(\mathrm{mm})$ (gray crosses and black dots, respectively). Movements of the arm ipsilateral to the stimulated SC are shown as open circles.

time locked to the target appearance but not movement onset (Pruszynski et al., 2010).

The movements to the screen elicited by SC stimulation might be added by the involvement of a larger (including cortical) network subserving goal-directed arm movements. It is tempting to compare our results with those elicited by electrical microstimulation to the precentral cortex described by Graziano et al. (2005). After one of our monkeys learned to perform arm movements to visual targets, his readiness to perform such reaches upon electrical stimulation increased. Therefore, training affects the monkey's state and by that the likelihood that an initial twitch during SC microstimulation completes into an action (Graziano et al., 2002, 2005).

The arm, shoulder, and trunk representations in the premotor cortices send fibers into the intermediate and deep layers of the 
monkey SC (Kuypers and Lawrence, 1967; Goldman and Nauta, 1976; Catman-Berrevoets et al., 1979; Fries, 1984, 1985; Stuphorn et al., 1996). Therefore, TSNs and collicular reach neurons contacted by these corticotectal fibers could represent a corticotecto-reticulo-spinal pathway providing information in parallel to the corticospinal pathway for reach movements of the forelimbs to the spinal cord (Kuypers et al., 1962; Anderson et al., 1971). Interestingly, Borra et al. (2010) found that both the hand area of the ventral premotor cortex F5a and F5p, an area hosting pyramidal tract neurons with mirror properties (Kraskov et al., 2009), and the anterior intraparietal area, which contains neurons responsive to shape, size, and orientation of objects to be grasped (Borra et al., 2012), send projections to the deep layers of the SC and underlying reticular formation, matching the areas identified in our study. Situated in this position, the SC could complement and/or modify the motor commands from cortical areas such as the PMC or the parietal area and thus influence the original motor plan. We can only speculate how collicular microstimulation involves these structures. Possibilities are ascending projections of the SC via thalamus to cortical structures and/or facilitation of reticular formation regions.

However, other explanations have to be disputed. Collicular microstimulation could recruit cortical regions via axon collaterals of antidromically activated corticotectal axons. Although this confound cannot be ruled out in any experiment using electrical microstimulation in interconnected neural networks, we think it is not very likely for the following reasons. First, our thresholds to elicit arm movements (median $30 \mu \mathrm{A}$ ) are well below mean currents necessary to antidromically activate corticotectal axons $(182,200$, or $25-1800 \mu \mathrm{A}$ for axons from LIP, FEF, or premotor cortex, respectively (Paré and Wurtz, 1997; Sommer and Wurtz, 2000; Reyes-Puerta and Hoffmann, 2010). Thresholds for orthodromic spikes in FEF or premotor cortex driven from SC are in a similar range (Sommer and Wurtz, 1998; Reyes-Puerta and Hoffmann, 2010). Second, according to Phillips (1959), Betz-cells in the cat's motor cortex show an early fascilitation followed by long-lasting depressed excitability after stimulation of pyramidal tract axons. Putative corticotectal axon collaterals contact inhibitory and excitatory neurons in layer 5 of monkey striate cortex (Briggs and Callaway, 2005). This depression or inhibition may be the reason for the extreme sparseness of spikes in cortical areas after stimulation of corticofugal axons (Sommer and Wurtz, 1998; Hoffmann et al., 2009). Finally, premotor activation has 7-9 times weaker effects on forelimb muscles (Boudrias et al., 2010) than M1, the forelimb region of which projects only sparsely to the SC (Tokuno et al., 1995).

Therefore, the high thresholds and the sparseness of orthodromically driven action potentials due to intracortical inhibition and the relatively weak effect of PMd compared with M1 on arm muscles make it rather unlikely that repetitive stimulation of recurrent collaterals of premotor corticotectal axons are a simple explanation for arm movements elicited from SC.

\section{Can the arm movements be explained by changes in the saliency map or visual phosphenes caused by microstimulation in the SC?}

The SC is involved in target selection for visually guided reach movements (Song et al., 2011) that are impaired by reversible SC inactivation (Nummela and Krauzlis, 2010). That increased saliency of a reach target or a spatial location on the collicular map created by microstimulation causes the arm movements is contradicted by the fact that, in the present study, arm movements were evoked only from a restricted area in the lateral SC. Micro- stimulation in the more medial part of the SC was never effective at the stimulus strengths used in either of the three monkeys, although it should cause the above-mentioned saliency effects. Therefore, we argue that microstimulation is effective only in the lateral area of SC because the density of TSNs and reach neurons is highest in this compartment of the SC.

\section{Collicular contribution to complex behavior}

Another way to elicit arm movements by electrical microstimulation in the deep layers of the SC could be the activation of the nucleus cuneiformis, a nucleus involved in flight and defensive behavior (for review, see Grillner et al., 1999). It was further identified as a structure that is involved in the generation of patterned locomotion (Shik and Orlovsky, 1976). Because the SC projects to the nucleus cuneiformis (Harting, 1977), electrical microstimulation in the intermediate and deep layers could activate the above-mentioned movement patterns. This possibility is especially interesting because, in the present study, defense-like behavior was sometimes but rarely observed after electrical microstimulation (but see DesJardin et al., 2013). Locomotion patterns were never observed.

In conclusion, our study indicates that the SC of the rhesus monkey contributes to forelimb movements, demonstrating a further component of the functional repertoire of this structure. It exemplifies that the monkey SC should not be seen as a unitary structure, but rather one consisting of many distinguishable layers and compartments with different functions due to their differential anatomical connections. The primate SC is therefore not merely an evolutionary relic constricted to the control of gaze and saliency; it has retained its full repertoire to contribute to complex action patterns primordially of tectal origin that became adopted by the neocortex in mammals.

\section{References}

Akert K (1949) The visual grasp reflex. Helv Physiol Acta 7:112-134.

Anderson ME, Yoshida M, Wilson VJ (1971) Influence of superior colliculus on cat neck motoneurons. J Neurophysiol 34:898-907. Medline Anderson ME, Yoshida M, Wilson VJ (1972) Tectal and tegmental influences on cat forelimb and hindlimb motoneurons. J Neurophysiol 35: 462-470. Medline

Borra E, Belmalih A, Gerbella M, Rozzi S, Luppino G (2010) Projections of the hand field of the macaque ventral premotor area F5 to the brainstem and spinal cord. J Comp Neurol 518:2570-2591. CrossRef Medline

Borra E, Gerbella M, Rozzi S, Tonelli S, Luppino G (2012) Projections to the superior colliculus from inferior parietal, ventral premotor, and ventrolateral prefrontal areas involved in controlling goal-directed hand actions in the macaque. Cereb Cortex. Advance online publication. Retrieved Dec. 12, 2012. doi:10.1093/cercor/bhs392. CrossRef

Boudrias MH, Lee SP, Svojanowsky S, Cheney PD (2010) Forelimb muscle representations and output properties of motor areas in the mesial wall of rhesus macaques. Cereb Cortex 20:704-719. CrossRef Medline

Briggs F, Callaway EM (2005) Laminar patterns of local excitatory input to layer 5 neurons in macaque primary visual cortex. Cereb Cortex 15:479488. CrossRef Medline

Buford JA, Davidson AG (2004) Movement-related and preparatory activity in the reticulospinal system of the monkey. Exp Brain Res 159:284300. CrossRef Medline

Castiglioni AJ, Gallaway MC, Coulter JD (1978) Spinal projections from the midbrain in monkey. J Comp Neurol 178:329-346. CrossRef Medline

Catman-Berrevoets CE, Kuypers HG, Lemon RN (1979) Cells of origin of the frontal projections to magnocellular and parvocellular red nucleus and superior colliculus in cynomolgous monkey-an HRP study. Neurosci Lett 12:41-46. CrossRef Medline

Corneil BD, Olivier E, Munoz DP (2002) Neck muscle responses to stimulation of monkey superior colliculus. I. Topography and manipulation of stimulation parameters. J Neurophysiol 88:1980-1999. Medline

Cowie RJ, Robinson DL (1994) Subcortical contributions to head move- 
ments in macaques. I. Contrasting effects of electrical stimulation of a medial pontomedullary region and the superior colliculus. J Neurophysiol 72:2648-2664. Medline

Davidson AG, Buford JA (2004) Motor outputs from the primate reticular formation to shoulder muscles as revealed by stimulus-triggered averaging. J Neurophysiol 92:83-95. CrossRef Medline

DesJardin JT, Holmes AL, Forcelli PA, Cole CE, Gale JT, Wellman LL, Gale K, Malkova L (2013) Defense-like behaviors evoked by pharmacological disinhibition of the superior colliculus in the primate. J Neurosci 33:150155. CrossRef Medline

Ewert JP (1984) Tectal mechanisms that underlie prey-catching and avoidance behavior in toads. In: Comparative neurology of the optic tectum (Vanegas H, ed), 247-416. New York: Plenum.

Freedman EG, Stanford TR, Sparks DL (1996) Combined eye-head gaze shifts produced by electrical stimulation of the superior colliculus in rhesus monkeys. J Neurophysiol 76:927-952. Medline

Fries W (1984) Cortical projections to the superior colliculus in the macaque monkey: a retrograde study using horseradish peroxidase. J Comp Neurol 230:55-76. CrossRef Medline

Fries W (1985) Inputs from motor and premotor cortex to the superior colliculus of the macaque monkey. Behav Brain Res 18:95-105. CrossRef Medline

Fuchs AF, Robinson DA (1966) A method for measuring horizontal and vertical eye movement chronically in the monkey. J Appl Physiol 21: 1068-1070. Medline

Gandhi NJ, Katnani HA (2011) Motor functions of the superior colliculus. Annu Rev Neurosci 34:205-231. CrossRef Medline

Goldman PS, Nauta WJ (1976) Autoradiographic demonstration of a projection from prefrontal association cortex to the superior colliculus in the rhesus monkey. Brain Res 116:145-149. CrossRef Medline

Grantyn A, Grantyn R (1982) Axonal patterns and sites of termination of cat superior colliculus neurons projecting in the tecto-bulbo-spinal tract. Exp Brain Res 46:243-256. CrossRef Medline

Graziano MS, Taylor CS, Moore T (2002) Complex movements evoked by microstimulation of precentral cortex. Neuron 34:841-851. CrossRef Medline

Graziano MS, Aflalo TN, Cooke DF (2005) Arm movements evoked by electrical stimulation in the motor cortex of monkeys. J Neurophysiol 94: 4209-4223. CrossRef Medline

Grillner S, Lund S (1968) The origin of a descending pathway with monosynaptic action on flexor motoneurones. Acta Physiol Scand 74:274-284. CrossRef Medline

Grillner S, Georgopoulos AP, Jordan LM (1999) Selection and initiation of motor patterns. In: Neurons, networks, and motor behavior (Stein PSG, Grillner S, Selverston A, Stuart DG, eds), pp 3-19. Boston: MIT.

Harting JK (1977) Descending pathways from the superior collicullus: an autoradiographic analysis in the rhesus monkey (Macaca mulatta). J Comp Neurol 173:583-612. CrossRef Medline

Hess WR, Burgi S, Bucher V (1946) Motor function of tectal and tegmental area. Monatsschr Psychiatr Neurol 112:1-52. CrossRef Medline

Hoffmann KP, Bremmer F, Distler C (2009) Visual response properties of neurons in cortical areas MT and MST projecting to the dorsolateral pontine nucleus or the nucleus of the optic tract in macaque monkeys. Eur J Neurosci 29:411-423. CrossRef Medline

Horn AK (2006) The reticular formation. Prog Brain Res 151:127-155. CrossRef Medline

Judge SJ, Richmond BJ, Chu FC (1980) Implantation of magnetic search coils for measurement of eye position: an improved method. Vis Res 20:535-538. CrossRef Medline

Klier EM, Wang H, Crawford JD (2003) Three-dimensional eye-head coordination is implemented downstream from the superior colliculus. J Neurophysiol 89:2839-2853. CrossRef Medline

Kraskov A, Dancause N, Quallo MM, Shepherd S, Lemon RN (2009) Corticospinal neurons in macaque ventral premotor cortex with mirror properties: a potential mechanism for action suppression? Neuron 64:922930. CrossRef Medline

Kuypers HG, Lawrence DG (1967) Cortical projections to the red nucleus and the brain stem in the rhesus monkey. Brain Res 4:151-188. CrossRef Medline

Kuypers HG, Fleming WR, Farinholt JW (1962) Subcorticospinal projections in the rhesus monkey. J Comp Neurol 118:107-137. CrossRef Medline
Lindner W (2004) Auswirkungen von Handbewegungen auf die Aktivität visuomotorischer Neurone im Colliculus superior des Rhesusaffen (Macaca mulatta). PhD thesis, Ruhr-University, Bochum, Germany.

Linzenbold W, Himmelbach M (2012) Signals from the deep: reach-related activity in the human superior colliculus. J Neurosci 32:13881-13888. CrossRef Medline

Matsuyama K, Mori F, Nakajima K, Drew T, Aoki M, Mori S (2004) Locomotor role of the corticoreticular-reticulospinal-spinal interneuronal system. Prog Brain Res 143:239-249. CrossRef Medline

May PJ (2006) The mammalian superior colliculus: laminar structure and connections. Prog Brain Res 151:321-378. CrossRef Medline

Meredith MA, Stein BE (1983) Interactions among converging sensory inputs in the superior colliculus. Science 221:389-391. CrossRef Medline

Meredith MA, Stein BE (1986a) Visual, auditory, and somatosensory convergence on cells in superior colliculus results in multisensory integration. J Neurophysiol 56:640-662. Medline

Meredith MA, Stein BE (1986b) Spatial factors determine the activity of multisensory neurons in cat superior colliculus. Brain Res 365:350-354. CrossRef Medline

Nudo RJ, Sutherland DP, Masterton RB (1993) Inter- and intra-laminar distribution of tectospinal neurons in 23 mammals. Brain Behav Evol 42:1-23. Medline

Nummela SU, Krauzlis RJ (2010) Inactivation of primate superior colliculus biases target choice for smooth pursuit, saccades, and button press responses. J Neurophysiol 104:1538-1548. CrossRef Medline

Olivier E, Chat M, Grantyn A (1991) Rostrocaudal and lateromedial density distributions of superior colliculus neurons projecting in the predorsal bundle and to the spinal cord: a retrograde HRP study in the cat. Exp Brain Res 87:268-282. Medline

Ottes FP, Van Gisbergen JA, Eggermont JJ (1986) Visuomotor fields of the superior colliculus: a quantitative model. Vis Res $26: 857-873$. CrossRef Medline

Paré M, Wurtz RH (1997) Monkey posterior parietal cortex neurons antidromically activated from superior colliculus. J Neurophysiol 78:34933497. Medline

Peterson BW, Pitts NG, Fukushima K (1979) Reticulospinal connections with limb and axial motoneurons. Exp Brain Res 36:1-20. Medline

Philipp R, Lindner W, Hoffmann KP (2006) How is the macaque superior colliculus involved in the execution of goal-directed hand-movements? Effects of electrical microstimulations in the intermediate and deep SClayers. FENS Abstr., vol. 3, A145.16.

Phillips CG (1959) Actions of antidromic pyramidal volleys on single Betz cells in the cat. Q J Exp Physiol Cogn Med Sci 44:1-25. Medline

Pruszynski JA, King GL, Boisse L, Scott SH, Flanagan JR, Munoz DP (2010) Stimulus-locked responses on human arm muscles reveal a rapid neural pathway linking visual input to arm motor output. Eur J Neurosci 32: 1049-1057. CrossRef Medline

Reyes-Puerta V, Hoffmann KP (2010) Program No. 582.10.2010 Neuroscience Meeting Planner, San Diego, CA: Society for Neuroscience. Online.

Reyes-Puerta V, Philipp R, Lindner W, Lünenburger L, Hoffmann KP (2009) Influence of task predictability on the activity of neurons in the rostral superior colliculus during double-step saccades. J Neurophysiol 101: 3199-3211. CrossRef Medline

Reyes-Puerta V, Philipp R, Lindner W, Hoffmann KP (2010) Role of the rostral superior colliculus in gaze anchoring during reach movements. J Neurophysiol 103:3153-3166. CrossRef Medline

Reyes-Puerta V, Philipp R, Lindner W, Hoffmann KP (2011) Neuronal activity in the superior colliculus related to saccade initiation during coordinated gaze-reach movements. Eur J Neurosci 34:1966-1982. CrossRef Medline

Robinson FR, Phillips JO, Fuchs AF (1994) Coordination of gaze shifts in primates: brainstem inputs to neck and extraocular motoneuron pools. J Comp Neurol 346:43-62. CrossRef Medline

Rubelowski JM, Menge M, Distler C, Rothermel M, Hoffmann KP (2013) Connections of the superior colliculus to shoulder muscles of the rat: a dual tracing study. Front Neuroanat 7:7-17. CrossRef Medline

Sahibzada N, Dean P, Redgrave P (1986) Movements resembling orientation and avoidance elicited by electrical stimulation of the superior colliculus in rats. J Neurosci 6: 723-733. Medline

Sailer U, Eggert T, Ditterich J, Straube A (2003) Predictive pointing movements and saccades toward a moving target. J Mot Behav 35:23-32. CrossRef Medline 
Schepens B, Stapley P, Drew T (2008) Neurons in the pontomedullary reticular formation signal posture and movement both as an integrated behavior and independently. J Neurophysiol 100:2235-2253. CrossRef Medline

Shik ML, Orlovsky GN (1976) Neurophysiology of locomotor automatism. Physiol Rev 56:465-501. Medline

Snyder LH (2000) Coordinate transformations for eye and arm movements in the brain. Curr Opin Neurobiol 10:747-754. CrossRef Medline

Sommer MA, Wurtz RH (1998) Frontal eye field neurons orthodromically activated from the superior colliculus. J Neurophysiol 80:3331-3335. Medline

Sommer MA, Wurtz RH (2000) Composition and topographic organization of signals sent from the frontal eye field to the superior colliculus. J Neurophysiol 83:1979-2001. Medline

Song JH, Rafal RD, McPeek RM (2011) Deficits in reach target selection during inactivation of the midbrain superior colliculus. Proc Natl Acad Sci U S A 108:E1433-E1440. CrossRef Medline

Stuphorn V, Bauswein E, Hoffmann K-P (1996) Cortico-collicular control of arm movements. In: Neural bases of motor behaviour. (Lacquaniti F, Viviani P, eds), 185-204. Dordrecht, The Netherlands: Kluwer Academic.

Stuphorn V, Hoffmann KP, Miller LE (1999) Correlation of primate supe- rior colliculus and reticular formation discharge with proximal limb muscle activity. J Neurophysiol 81:1978-1982. Medline

Tokuno H, Takada M, Nambu A, Inase M (1995) Direct projections from the orofacial region of the primary motor cortex to the superior colliculus in the macaque monkey. Brain Res 703:217-222. CrossRef Medline

Walton MM, Bechara B, Gandhi NJ (2007) Role of the primate superior colliculus in the control of head movements. J Neurophysiol 98:20222037. CrossRef Medline

Werner W (1993) Neurons in the primate superior colliculus are active before and during arm movements to visual targets. Eur J Neurosci 5:335340. CrossRef Medline

Werner W, Dannenberg S, Hoffmann KP (1997a) Arm-movement-related neurons in the primate superior colliculus and underlying reticular formation: comparison of neuronal activity with EMGs of muscles of the shoulder, arm and trunk during reaching. Exp Brain Res 115:191-205. CrossRef Medline

Werner W, Hoffmann KP, Dannenberg S (1997b) Anatomical distribution of arm-movement-related neurons in the primate superior colliculus and underlying reticular formation in comparison with visual and saccadic cells. Exp Brain Res 115:206-216. CrossRef Medline

Wurtz RH, Goldberg ME (1971) Superior colliculus cell responses related to eye movements in awake monkeys. Science 171:82-84. CrossRef Medline 